ANNALES

UNIVERSITATIS MARIAE CURIE-SKŁODOWSKA

LUBLIN - POLONIA

VOL. LXXII, 1

SECTIO AA

2017

\title{
Chlorogenic acids - their properties, occurrence and analysis
}

\author{
Marta Gil ${ }^{*}$ and Dorota Wianowska \\ Department of Chromatographic Methods, Faculty of Chemistry, \\ Maria Curie-Skłodowska University \\ pl. Maria Curie-Skłodowska 3, 20-031 Lublin, Poland \\ e-mail:martagil.24@gmail.com
}

Chlorogenic acids (CQAs), the esters of caffeic acid and quinic acid, are biologically important phenolic compounds present in many plant species. Nowadays much is known from their prohealth properties, including anti-cancer activity. Yet, the supposition that they may be helpful in fighting obesity and modify glucose-6-phosphatase involved in glucose metabolism have led to a revival of research on CQAs properties and their natural occurrence. Much attention is also paid to the proper analysis of CQAs content in plants and plant products due to the fact that the main CQAs representative in nature i.e. 5-O-caffeoylquinic acid (5-CQA) is commonly employed as a quality marker in the control of various natural products.

The common procedures used so far for CQAs determination in plants involve conventional long lasting solvent extraction realized at higher temperatures prior to chromatographic analysis. The drawbacks associated to the conventional extraction techniques have led to the search for new alternative extraction processes that additionally could improve extracts quality. The latter is particularly important as regards CQAs applications, and the fact that these compounds easily transform/degrade to others. According to reports, the conventional heating of 5-CQA in the presence of water causes its isomerization and transformation. The reports prove that 5-CQA not only isomerizes to 3 - and $4-O$-caffeoylquinic acid, but 
also undergoes other transformations such as esterification and reactions with water. Hence, in the attempt to improve the process of chlorogenic acids extraction and to make it more effective and environmentally friendly, innovative so-called "enhanced" techniques of extraction have been recently developed and applied. To guarantee the proper analysis of compounds with very similar properties forming the chlorogenic acids family and their numerous transformation/degradation products, hyphenated techniques, in particular LC-MS, are currently being used.

The purpose of this review is to summary and overview of the sources, properties, and methods which have been developed to improve the extraction and analysis of chlorogenic acids in plants and plant products, with particular reference to 5-CQA and 1,3-diCQA as these compounds of the CQAs family with many beneficial effects on human health.

\section{INTRODUCTION}

Chlorogenic acids (CQAs) are naturally occurring phenolic compounds found in all higher plants $[1,2]$. Due to their various biological properties, such as antispasmodic [3], antioxidant [4], inhibition of the HIV-1 integrase [5,6] and inhibition of the mutagenicity of carcinogenic compounds [3], they are very important plant secondary metabolites. In the light of recently published results [7-12], they are also supposed to be helpful in fighting obesity and modify glucose-6phosphatase involved in glucose metabolism. These suppositions, although unproven, were sufficient to a revival of research on CQAs properties and their natural occurrence, the more that new applications of CQAs are suggested in pharmaceuticals, foodstuffs, food additives and cosmetics.

From the chemical point of view, CQAs constitute a large family of esters formed between quinic acid and one or more trans-hydroxycinnamic acid derivatives, most commonly caffeic, $p$-coumaric, and ferulic acid [2]. Taking into account the identity, number and position of the acyl residues, in this group of compounds may be distinguished:

- mono-esters of caffeic, p-coumaric and ferulic acid: caffeoylquinic acids (CQAs), p-coumaroylquinic acids (pCoQAs) and feruloylquinic acids (FQAs), respectively,

- di-esters, tri-esters and the single tetra-ester of caffeic acid: diCQAs, triCQAs and tetraCQA, respectively, 
- mixed di-esters of caffeic and ferulic acid or caffeic and sinapic acid: caffeoylferuloylquinic acids (CFQAs) and caffeoylsinapoylquinic acids (CSiQAs);

- mixed esters involving various permutations of one or three caffeic acid residues with one or two dibasic aliphatic acid residues e.g. glutaric, oxalic, succinic.

Fig. 1 presents the general structures of mono- and dicaffeoylquinic, p-coumaroylquinic, and feruloylquinic acids together with structures of the most characteristic representatives of mono- and dicaffeoylquinic acids for plants i.e. 5-O-caffeoylquinic acid and 1,3-di- $O$-caffeoylquinic acid.

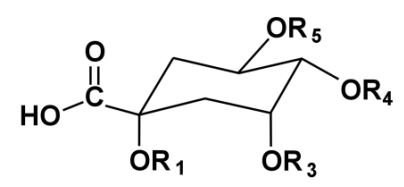

Quinic acid

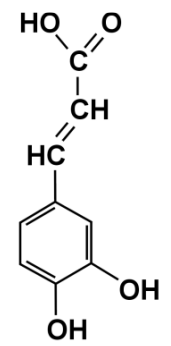

Caffeic acid<smiles>O=C(O)/C=C/c1ccc(O)cc1</smiles>

$P$-coumaric acid<smiles>COc1cc(/C=C/C(=O)O)ccc1O</smiles>

Ferulic acid

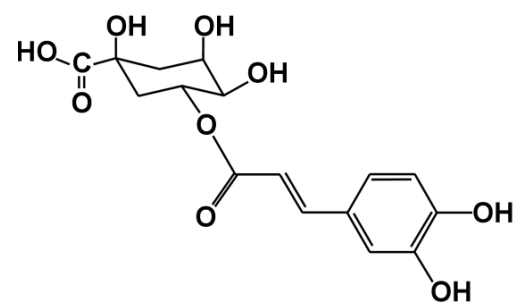

5-O-caffeoylquinic acid<smiles>O=C(/C=C/c1ccc(O)c(O)c1)OC1CC(O)C(O)CC(OC(=O)/C=C/c2ccc(O)c(O)c2)(C(=O)O)C1</smiles>

1,3-di- $O$-caffeoylquinic acid

\begin{tabular}{ccccccc}
\hline No. & Name and & Abbreviation & $\mathrm{R}_{1}$ & $\mathrm{R}_{3}$ & $\mathrm{R}_{4}$ & $\mathrm{R}_{5}$ \\
\hline 1 & 1- $O$-caffeoylquinic acid & 1-CQA & $\mathrm{C}$ & $\mathrm{H}$ & $\mathrm{H}$ & $\mathrm{H}$ \\
2 & $\begin{array}{l}\text { 3- } O \text {-caffeoylquinic acid } \\
\text { (neochlorogenic acid) }\end{array}$ & 3-CQA & $\mathrm{H}$ & $\mathrm{C}$ & $\mathrm{H}$ & $\mathrm{H}$ \\
3 & $\begin{array}{l}\text { 5- } O \text {-caffeoylquinic acid } \\
\text { (chlorogenic acid) }\end{array}$ & 5-CQA & $\mathrm{H}$ & $\mathrm{H}$ & $\mathrm{H}$ & $\mathrm{C}$ \\
4 & $\begin{array}{l}\text { 4- } O \text {-caffeoylquinic acid } \\
\text { (cryptochlorogenic acid) } \\
5\end{array}$ & 4-CQA & $\mathrm{H}$ & $\mathrm{H}$ & $\mathrm{C}$ & $\mathrm{H}$ \\
1,3-di- $O$-caffeoylquinic acid & 1,3-diCQA & $\mathrm{C}$ & $\mathrm{C}$ & $\mathrm{H}$ & $\mathrm{H}$ \\
\hline
\end{tabular}


cd. Fig. 1.

\begin{tabular}{|c|c|c|c|c|c|c|}
\hline No. & Name and & Abbreviation & $\mathrm{R}_{1}$ & $\mathrm{R}_{3}$ & $\mathrm{R}_{4}$ & $\mathrm{R}_{5}$ \\
\hline 6 & 1,4-di- $O$-caffeoylquinic acid & 1,4-diCQA & $\mathrm{C}$ & $\mathrm{H}$ & $\mathrm{C}$ & $\mathrm{H}$ \\
\hline 7 & 1,5-di- $O$-caffeoylquinic acid & 1,5-diCQA & $\mathrm{C}$ & $\mathrm{H}$ & $\mathrm{H}$ & $\mathrm{C}$ \\
\hline 8 & 3,4-di- $O$-caffeoylquinic acid & 3,4-diCQA & $\mathrm{H}$ & $\mathrm{C}$ & $\mathrm{C}$ & $\mathrm{H}$ \\
\hline 9 & 3,5-di- $O$-caffeoylquinic acid & 3,5-diCQA & $\mathrm{H}$ & $\mathrm{C}$ & $\mathrm{H}$ & $\mathrm{C}$ \\
\hline 10 & 4,5-di- $O$-caffeoylquinic acid & 4,5-diCQA & $\mathrm{H}$ & $\mathrm{H}$ & $\mathrm{C}$ & $\mathrm{C}$ \\
\hline 11 & 1-O-p-coumaroylquinic acid & $1-p \mathrm{CoQA}$ & $p \mathrm{Co}$ & $\mathrm{H}$ & $\mathrm{H}$ & $\mathrm{H}$ \\
\hline 12 & 3-O-p-coumaroylquinic acid & 3-pCoQA & $\mathrm{H}$ & $p \mathrm{Co}$ & $\mathrm{H}$ & $\mathrm{H}$ \\
\hline 13 & 5-O-p-coumaroylquinic acid & 5-pCoQA & $\mathrm{H}$ & $\mathrm{H}$ & $\mathrm{H}$ & $p \mathrm{Co}$ \\
\hline 14 & 4-O-p-coumaroylquinic acid & 4- $p$ CoQA & $\mathrm{H}$ & $\mathrm{H}$ & $p C o$ & $\mathrm{H}$ \\
\hline 15 & 1,3-di-O-p-coumaroylquinic acid & 1,3-dipCoQA & $p C o$ & $p \mathrm{Co}$ & $\mathrm{H}$ & $\mathrm{H}$ \\
\hline 16 & 1,4-di- $O$ - $p$-coumaroylquinic acid & 1,4-dipCoQA & $p \mathrm{Co}$ & $\mathrm{H}$ & $p \mathrm{Co}$ & $\mathrm{H}$ \\
\hline 17 & 1,5 -di- $O$ - $p$-coumaroylquinic acid & 1,5-dipCoQA & $p \mathrm{Co}$ & $\mathrm{H}$ & $\mathrm{H}$ & $p \mathrm{Co}$ \\
\hline 18 & 3,4-di- $O$ - $p$-coumaroylquinic acid & 3,4-dipCoQA & $\mathrm{H}$ & $p \mathrm{Co}$ & $p$ Co & $\mathrm{H}$ \\
\hline 19 & 3,5-di- $O$ - $p$-coumaroylquinic acid & 3,5-dipCoQA & $\mathrm{H}$ & $p$ Co & $\mathrm{H}$ & $p \mathrm{Co}$ \\
\hline 20 & 4,5-di- $O$ - $p$-coumaroylquinic acid & 4,5-dipCoQA & $\mathrm{H}$ & $\mathrm{H}$ & $p \mathrm{Co}$ & $p \mathrm{Co}$ \\
\hline 21 & 1- $O$-feruloylquinic acid & 1-FQA & $\mathrm{F}$ & $\mathrm{H}$ & $\mathrm{H}$ & $\mathrm{H}$ \\
\hline 22 & 3-O-feruloylquinic acid & 3-FQA & $\mathrm{H}$ & $\mathrm{F}$ & $\mathrm{H}$ & $\mathrm{H}$ \\
\hline 23 & 5-O-feruloylquinic acid & 5-FQA & $\mathrm{H}$ & $\mathrm{H}$ & $\mathrm{H}$ & $\mathrm{F}$ \\
\hline 24 & 4-O-feruloylquinic acid & 4-FQA & $\mathrm{H}$ & $\mathrm{H}$ & $\mathrm{F}$ & $\mathrm{H}$ \\
\hline 25 & 1,3-di- $O$-feruloylquinic acid & 1,3-diFQA & $\mathrm{F}$ & $\mathrm{F}$ & $\mathrm{H}$ & $\mathrm{H}$ \\
\hline 26 & 1,4-di-O-feruloylquinic acid & 1,4-diFQA & $\mathrm{F}$ & $\mathrm{H}$ & $\mathrm{F}$ & $\mathrm{H}$ \\
\hline 27 & 1,5 -di- $O$-feruloylquinic acid & 1,5-diFQA & $\mathrm{F}$ & $\mathrm{H}$ & $\mathrm{H}$ & $\mathrm{F}$ \\
\hline 28 & 3,4-di-O-feruloylquinic acid & 3,4-diFQA & $\mathrm{H}$ & $\mathrm{F}$ & $\mathrm{F}$ & $\mathrm{H}$ \\
\hline 29 & 3,5-di-O-feruloylquinic acid & 3,5-diFQA & $\mathrm{H}$ & $\mathrm{F}$ & $\mathrm{H}$ & $\mathrm{H}$ \\
\hline 30 & 4,5-di- $O$-feruloylquinic acid & 4,5-diFQA & $\mathrm{H}$ & $\mathrm{H}$ & $\mathrm{F}$ & $\mathrm{F}$ \\
\hline
\end{tabular}

Q- quinic acid, C-caffeic acid, $p$ Co- $p$-coumaric acid, F- ferulic acid

Fig. 1. Structures of mono- and dicaffeoylquinic, p-coumaroylquinic, and ferulylquinic acids 
One of significant features of CQAs is their chemical instability and formation/degradation to other compounds, including chlorogenic acids representatives [13-16]. According to report [15], the conventional heating of 5-O-caffeoylquinic acid (5-CQA) in the presence of water causes its isomerization and transformation. In [16] it was proved that 5-CQA not only isomerizes to 3-O-caffeoylquinic acid and 4-O-caffeoylquinic acid, but also undergoes other transformations such as esterification and reaction with water i.e. hydrolysis and/or addition of water molecule to the double bond. These processes take place not only in CQAs solutions but also during their isolation from plant materials and they could lead to obtain extracts with lower content of biologically active phenolic compounds.

Recently, there has been an increased interest in natural products rich in chlorogenic acids. Consequently, more efficient extraction methods, leading to obtain extracts with enhanced CQAs content and reduced content of their degradation products, are being sought. Unfortunately, the elimination/limitation of CQAs degradation/transformation is not the only problem in the CQAs determination in plants or plant products. The number of compounds needed to be identified during a single analysis is steadily increasing, through the number of commercially available standards is limited to just a few. This fact, in the face of the large number of CQAs with very similar properties and their tendency for easy formation of transformation/degradation products during their extraction, causes that CQAs analysis is not easy. Recently, more and more often it is realized by means of hyphenated techniques, in particularly using LC-MS ${ }^{\mathrm{n}}$.

The aim of this review is to summarize and give an overview of the sources, properties, and methods that have been developed to improve the extraction and analysis of chlorogenic acids in plants and plant products, with special attention to 5-O-caffeoylquinic acid and 1,3-di- $O$-caffeoylquinic acid as these compounds of the CQAs family with many beneficial effects on human health.

\section{CQAS OCCURRENCE}

CQAs belong to very common plant constituents. They are present, for example, in apples, stone fruits (peaches, nectarines, plums, lychees, mangoes, cherries), berry fruits (blueberries, blackcurrants, blackberries, bilberry), brassica vegetables (kale, cabbage and Brussels sprouts), 
apiaceae (celery, carrots, caraway and coriander), and others miscellaneous vegetables like corn salad, anise stars and potato [1, 2, 17-30]. Nevertheless, despite their high prevalence, they are believed to be the most characteristic constituents of plants from Asteraceae family, such as artichoke (Cynara scolymus), black salsify (Scorzonera hispanica L.), purple coneflower (Echinacea purpurea L. Moench), common yarrow (Achillea millefolium L.), milk thistle (Silybum marianum L. Gaertner), coltsfoot (Tussilago farfara L.), tansy (Tanacetum vulgare L.), chamomile (Matricaria chamomilla L.) [1, 2, 31-44]. Yet, even if these compounds are the most characteristic for the plant family, the CQAs content is very differentiated. According to Lattanzio et al. [31-44], the total content of CQAs in artichoke ranges from $8 \%$ on dry matter basis in young artichoke tissues to less of $1 \%$ in senescent ones. Of the total content of the CGAs in this plant, 5-CQA is the most represented single component (39\% of all CQAs in the artichoke), followed by 1,5-diCQA (21\%) and 3,4-diCQA (11\%). The content of 1,3-diCQA is $1.5 \%$ of all CQAs. For contrast, black salsify provide $180 \mathrm{mg} / \mathrm{kg}$ 5-CQA with little or none content of the other CQA derivatives [35].

CQAs are present in all parts of plants (seeds, roots, tubers, leaves and flowers) as well as in different products prepared from them, in particularly in beverages, such as coffee, green and black tea, yerba mate, juice, infusion and even wine. It should be emphasized, however, the CQAs qualitative and quantitative composition is various and dependent not only on plant parts but also on the plant physiological stage, the conditions of storage and plants processing, especially when the processing is accompanied by heat and/or enzymatic treatment.

Whole apples have been reported to contain $62-358 \mathrm{mg} / \mathrm{kg}$ CQAs [19-21]. They are found at similar concentrations in the apple's isolated flesh and skin (mean values 30-60 mg/kg) but are absent in the seeds and pomace [21-23]. With the change of apples variety changes not only the total CQAs content but also the CQAs composition. Yet, regardless of the apples variety, 5-CQA is the main constituent. Variability of quantitative and qualitative composition of CQAs is also characteristic of juices and ciders. In commercially available juices, the CQAs content can be from undetectable level up to $208 \mathrm{mg} / \mathrm{dm}^{3}$ 5-CQA alone [19], and in ciders in the range of $11-480 \mathrm{mg} / / \mathrm{dm}^{3}$ or even higher when these are produced from the fruit of Sorbus domestica, known from a high 5-CQA content $(1500 \mathrm{mg} / \mathrm{kg})$ [24].

The mean CQAs content in stone fruits is in the range 150-600 mg/ kg. Compared with apples, in the fresh stone fruits 3-CQA 
is more prominent relative to 5-CQA. However, in peach and apricot juice the 5-CQA level is about 3-4 times greater than 3-CQA, with the total CQAs content reaches 9 and $4 \mathrm{mg} / \mathrm{dm}^{3}$, respectively [1].

The CQAs content in potato tubers have been reported in the range $500-1200 \mathrm{mg} / \mathrm{kg}$ dry basis [25-26]. They are concentrated in the peel where they may reach level of $2-5 \mathrm{~g} / \mathrm{kg}$ or even higher [27]. Of the CQAs, the di-CQAs are present in a little amounts while the mono-CQAs amounts are greater. After harvesting period, the content of CQAs rises slowly, particularly during tubers storage in the light or during wound healing.

One of the richest dietary sources of CQAs are coffee beans. Depending on the species, green coffee beans contain 6-12\% CQAs on the dry weight of the coffee beans. During roasting there is a progressive degradation and transformation of CQAs. It is estimated that 8-10\% CQAs are lost for every $1 \%$ of the dry weight of the total CQAs amount in the coffee beans. Clifford and Walker evaluated [28] that a $200 \mathrm{~cm}^{3}$ cup of roast and ground coffee might supply from $20 \mathrm{mg}$ 5-CQA (weak brew, very dark roast) up to $675 \mathrm{mg}$ 5-CQA (strong brew, very pale roast robusta). Soluble coffee powder ( $2 \mathrm{~g}$ per cup) has been reported to consist of 50-150 mg of 5-CQA [1].

Yerba mate, a traditional South American beverage prepared from the leaves of Ilex paraguariensis A. St.-Hil., is rich in mono- and diCQAs. There have been few investigations of the brew composition but green mate material bought and brewed in Europe provided 107-133 mg CQAs per approx. $200 \mathrm{~cm}^{3}$ of which diCQA represented one third. In contrast, roasted mate provided 16-41 mg CQAs per $200 \mathrm{~cm}^{3}$ [37]. Mazzafera [38] reported that when authentic material is brewed in the traditional manner (50-60 g leaves per liter boiling water) $480-520 \mathrm{mg}$ of 5-CQA is extracted.

In view of the above presented examples showing the CQAs content in plants, it can be stated that among all CQAs the most ubiquitous compound, that is present in larger quantities, is 5-CQA. For these reasons 5-CQA is commonly employed as a quality marker in the control of various natural products and it belongs, undoubtedly, to the most frequently studied representatives of the chlorogenic acids family. The other reasons for researchers interest in 5-CQA include: its important role in the plant's response to stress, is an important biosynthetic intermediate, for example, in lignin biosynthesis, and exhibiting antiviral, antibacterial, antifungal and anticarcinogenic effects combined with relatively low toxicity and side effects $[5,8,10,11,29]$. The other compound that focus 
the researchers attention, due to exhibited biological properties, is 1,3-diCQA. This compound, in contrast to 5-CQA, is mainly characteristic for the Asteraceae family, especially for artichoke. Yet, despite a rare occurrence and a low content in plants, 1,3-diCQA is the most wellknown and frequently investigated derivative of dicaffeoylquinic acids [31]. 1,5-diCQA and 3,4-diCQA, though they occur in larger quantities in many plants, they are not so intensively investigated by researchers [31-35].

\section{THE BEGINNINGS OF CQAS CHEMISTRY}

The first report on chlorogenic acids, concerning the properties of chlorogenic acid alone, most likely appeared in 1837 [35]. The first documented reference comes from 1844. In this year, Rochleder [35] noticed that caffeine in green coffee beans could combine with an acid that could be precipitated with lead salts. The free acid, generated by the treatment of precipitate with sulfuric acid, gave a yellow color on the addition of ammonia. Two years later the same researcher proposed an empirical formula of $\mathrm{C}_{16} \mathrm{H}_{9} \mathrm{O}_{8}$ for the free acid and reported that the yellow ammonical solution become green on exposure to oxygen [35]. (That is why the compound despite absence of chlorine is called "chloro".) Later that year, Payen [35] announced the isolation of a crystalline potassium caffeine chloroginate that formed about $3.5 \%$ of green coffee beans and proposed an empirical formula of $\mathrm{C}_{14} \mathrm{H}_{8} \mathrm{O}_{7}$. Gorter [35] reported a melting point at $206-207^{\circ} \mathrm{C}$ for pure white crystals of chlorogenic acid, and proposed an empirical formula of $\mathrm{C}_{32} \mathrm{H}_{38} \mathrm{O}_{19}$. Alkaline hydrolysis at low temperatures yielded caffeic acid (CA) and quinic acid (QA) in equimolar quantities. To make this observation compatible with the proposed empirical formula, Gorter suggested that CA associate with QA to produce hemi-CQA, two molecules of which condensed to give chlorogenic acid. In 1920, Freudenberg reported that the enzyme tannase hydrolyze chlorogenic acid to equimolar quantities of CA acid and QA. In 1932, Fischer and Dangschat deduced that chlorogenic acid is 3-caffeoylquinic acid. (According to a pre-IUPAC nomenclature for cyclitols, the positional number of carbon atoms in the quinic acid ring were assigned in an anticlockwise manner.) Under current IUPAC recommendations (positional number assigned to the carbon atoms of the quinic acid ring in clockwise sense), 3-caffeoylquinic acid is now designated 5-O-caffeoylquinic acid (5-CQA, see Fig. 1) [35]. 
The first report on dicaffeoylquinic acid derivatives was prepared by Panizzi and Scarpati [45] and concerned the isolation of cynarin from artichoke leaves. In these report, cynarin was characterized as a yellowish-colored crystalline substance exhibited left-handed rotatory power and a weak acid reaction, that is slightly stable in air alkaline solution and change the color to green in the presence of ferric chloride. The cynarin structure was initially described as 1,4- $O$-dicaffeoylquinic acid [45]. Later, the compound was identified as 1,5-O-dicaffeoylquinic acid by the same researchers. Now, according to IUPAC recommenddation, cynarin is called 1,3-O-dicaffeoylquinic acid (see Fig. 1).

\section{CQAS PROPERTIES}

Compounds belonging to the chlorogenic acid family exhibit very differentiated physicochemical properties dependent on the identity, number and position of the acyl residues esterified with the quinic acid as well as on the functional groups present on the aromatic moiety of the acyl residues.

The monoCQAs, in general, and the less polar diCQAs, in particular, are more soluble in the lower alcohols or alcohol-water mixtures. They are insoluble in benzene, chloroform, and petroleum ether. The diCQAs, in addition to the lower alcohols, are well dissolved in ethyl acetate, butyl acetate, and acetone. Taking into account the position of acyl residue in the quinic acid, water solubility declines in the sequence: $1->3->4->5$. For diCQAs, the order can be presented as follows: 1,3- $>1,4->1,5-$ $>3,4->3,5->4,5$-. In general, those CQAs with a greater number of free equatorial hydroxyl groups in the quinic acid residue are more water soluble than those with a greater number of free axial hydroxyl groups [46]. As to the influence of functional groups present on the aromatic moiety of the acyl residues, a hydroxyl group raises the polarity whereas a methoxy group reduces it. Concerning the effect of the identity of hydroxycinnamic acid derivatives, water solubility declines in the following order: 5-CQA > 5-CoQA > 5-FQA [35].

In the case of CQAs, one of the characteristic processes widely characterized in literature and responsible for modifying the structure of CQAs is acyl migration $[47,48]$. This process describes the migration of cinnamoyl moieties from one quinic acid alcohol group to another. It is responsible for regioisomerization of appropriate CQAs, thus it constitutes a special case of transesterification reaction. The migration 
process is temperature and $\mathrm{pH}$ dependent with increased transesterification taking place at basic $\mathrm{pH}[15,47]$. Moreover, the process can be inter- and/or intramolecular. According to [47], under aqueous basic conditions the intramolecular acyl migration in monoCQAs is fully reversible. Through intramolecular acyl migration in monoCQAs, for example, 5-CQA first isomerizes to 4-CQA (also known as cryptochlorogenic acid), then to 3-CQA (neochlorogenic acid), and finally to 1-CQA [49]. It should be added, that among the all 5-CQA isomers the presence of 3- and 4-CQA was confirmed in plants, the 1-CQA isomer is known only from theoretical considerations [2]. Similarly to the monoCQAs, the diCQAs could also undergo the intramolecular acyl migration. Yet, the monoCQAs are generally much more stable than the diCQAs under the same conditions. Taking into account the diCQAs stability, in [50] it was reported that 4,5-diCQa is much more stable than 3,4-diCQA and 3,5-diCQA. Citing the authors of this report, this might be due to the fact that diCQAs are more stable when the ester bond link to the quinic acid exist as an equatorial bond rather than axial one. Only one ester bond of 3,4-diCQA and 3,5-diCQA exist as an equatorial bond while all ester bonds of 4,5-diCQA exist as equatorial bonds.

Apart from the acyl migration process, researchers reported another chemical changes for CQAs, such as hydrolysis of the ester bond, decarboxylation of cinnamoyl moieties, epimerization at the quinic acid, dehydration, lactones formation, and reaction with water or methanol $[2,15,35]$. It should be added that the above mentioned processes can compete with each other, as in the case of hydrolysis and acyl migration competition under aqueous basic conditions [47].

CQAs are highly susceptible to the influence of temperature. As temperature increase, they are not only more easily subjected to intramolecular isomerization and transesterification but also to degradation. The diCQAs degrade to the corresponding monoCQAs, and then to caffeic and quinic acid. The amount of each formed component depends on the heating time and temperature $[3,14,16]$. According to [50], total of eight degradation products of 3,4-diCQA, six degradation products of 3,5-diCQA, four degradation products of 1,3-diCQA, and three degradation products of 4,5-diCQA were identified in the diCQAs solutions. Only two degradation products of 3-CQA, three degradation products of 5-CQA, and four degradation products of 4-CQA were detected and identified in the monoCQAs solutions [50].

The study of the stability of CQAs in two solvents (methanol and aqueous methanol solution, $50 \% \mathrm{v} / \mathrm{v}$ ) kept in brown glass bottles at $4{ }^{\circ} \mathrm{C}$ 
showed slow degradation of the CQAs. Meanwhile, noticeable decreases in concentrations of CQAs were observed when kept in transparent glass at room temperature. CQAs degraded easily in methanol. According to the authors it was probably because increasing the concentrations of the respective adducts or esters of methanol [50].

CQAs are photosensitive and when they are exposed in ultraviolet or visibly light undergo trans-cis isomerization [43]. Isomerization kinetics is affected by irradiation time, wavelength and temperature. Yet, for samples stored at room temperature in methanol, significant degradation of monoCQAs was observed after 7 days their exposition to the light [50]. This may suggest that single factor, such as temperature, light or solvent has little effect on the stabilities of monoCQAs. Under dual factors of light and temperature, both mono- and diCQAs decompose easily $[15,47,50]$.

\section{PRO-HEALTH BIOLOGICAL ACTIVITY OF CQAS}

There are several advantageous health properties associated to the family of CQAs, such as hepatoprotective and choleretic activities, antioxidant, antiviral, antibacterial, anti-cancer and anti-inflammantory properties, modulation of gene expression of antioxidant enzymes, reduction of the risk of cardiovascular disease via suppressing P-selectin expression on platelets, and reduction of the relative risk of diabetes type 2 and Alzhaimer's disease [5-13, 51] (Fig. 2).

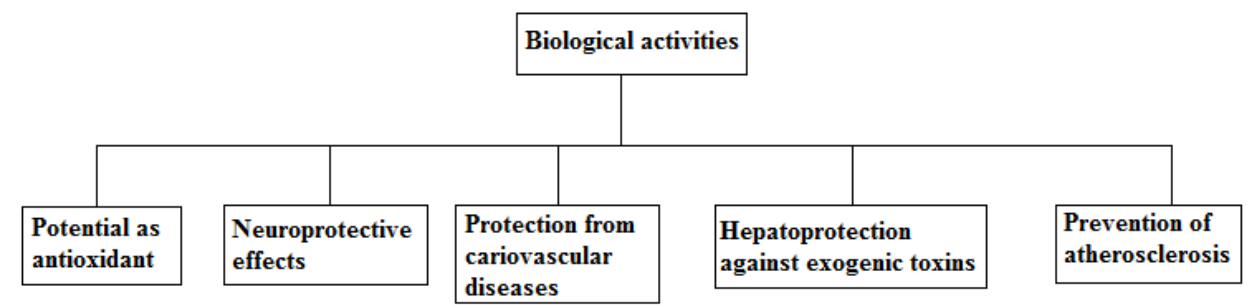

Fig. 2. Overview of chlorogenic acids biological activities.

Some of these properties are already well known and tested, others are not yet proven and are now under close scrutiny. This is, for example, the case of the supposition that CQAs may be helpful in fighting obesity and modulate the glucose-6-phosphatase involved in glucose metabolism $[12,13]$, and that they are a novel class of antiviral compounds, namely 
inhibitors of integrase, being potent inhibitors of HIV-1 replication, both in vitro and in vivo $[5,6,52]$.

Finally, it should be emphasized that despite the abundance of data demonstrating CQAs biological activities, some of them are still controversial. This is the case with their antioxidant properties. CQAs have been reported to inhibit the formation of reactive oxygen species and act as their scavengers, thus they may play beneficial role in the prevention of oxidative and age-related diseases [4, 5, 7]. According to new results however the issue, whether these compounds are potent antioxidants or pro-oxidants, it remains debatable. This is a consequence of the fact that CQAs properties switch from anti- to pro-oxidant activity, depending on their concentration, the presence of free transition metal ions, or on their redox status [35[35]].

In the view of the CQAs biological properties and their high susceptibility to the negative impact of surroundings (solvent type, $\mathrm{pH}$, temperature and even light) it is obvious why so many efforts have been undertaken to modify the way in which the compounds are isolated. Searching for new and alternative methodologies of CQAs extraction from plants is additionally supported by fact, that some of those compounds can be found in nature at very low concentrations. Thus, to obtain their sufficient amounts very effective isolation methods are needed. All the more that their structural diversity and complexity make chemical synthesis rather unprofitable.

\section{ISOLATION OF CAFFEOYLQUINIC ACIDS}

The common procedures used so far for determination of compounds in plants and related products involve two-step processes. In the first one, the compounds are liberated from pre-prepared sample matrix. In the second, they are analysed using, more frequently, chromatographic techniques. Depending on the sample matrix type, different procedures are applied for sample pre-treatment. Solid samples, such as plants and solid food stuffs, are usually homogenized, what may be preceded by lyophilisation or freezing with liquid nitrogen. Liquid samples, such as beverages, are usually first filtered and/or centrifuged, and then they are subjected either direct analysis or, what is more common to enhance the determination selectivity, they are subjected further steps of preparation.

To fully isolate the compounds released from matrices and/or to concentrate them a broad range of sample preparation techniques 
(e.g. distillation, sublimation, extraction to gas, liquid or solid phase) are currently being used. Most approaches to plant components analysis involve the application of liquid extraction methods, such as extraction in the Soxhlet apparatus, under reflux and maceration. These are so-called conventional liquid extraction techniques. Their extraction ability is based on the extracting power of different solvents and the application of heat and/or mixing. The conventional techniques are known from many disadvantages, such as time-consuming, relatively high solvent consumption, often unsatisfactory reproducibility and poor extraction of polar substances. Despite these drawbacks, however, the techniques are still commonly applied, mainly due to the simplicity of their use. To present properly the techniques used for CQAs extraction, it should be added, that the Soxhlet extraction is used less often. Nevertheless, this technique is still considered as one of the reference method to compare isolation efficiency of newly developed methodology.

In an attempt to reduce or eliminate the drawbacks of the conventional liquid extraction methods and to improve the extraction process innovative extraction methods such as microwave-, ultrasound-, and pressure-assisted extraction have been developed and introduced. These techniques, additionally, could improve extracts quality what is important taking into account the CQAs applicability as pro-health additives to foods and supplements.

\subsection{Ultrasound Assisted Solvent Extraction}

The mechanism of ultrasounds in liquids relies on the mechanical effect caused by the implosion of cavitational bubbles. The implosion of cavitation bubbles generates macro-turbulence, high-velocity interparticle collisions and perturbation in micro-porous particles of the natural materials which accelerates diffusion and enhances the mass transfer phenomena [53]. The increasing interests on applying ultrasounds to plants and plant products extraction lies in its advantage on reducing extraction time and increasing yield of heat-sensitive compounds at lower processing temperatures [54]. This is because the technique provides the greater opportunity of enhancing its extraction ability. Apart from the careful choice of an appropriate solvent characteristic for the conventional techniques, the process can be further optimized and this is an important part of the ultrasound-assisted solvent extraction (UASE) process. During the optimization, ultrasounds frequency, their amplitude, number of the applied extraction cycles, irradiation time and nominal output power are taken into consideration. Another advantageous feature of UASE, that is 
equally important, is the cost of equipment necessary for the technique. The cost is low, as the process is most often performed in ultrasonic baths being in each laboratory. Yet, the process can be realized in the different way, applying an ultrasonic disintegrator. In this case, the ultrasound emitting tip is directly immersed in the extraction mixture, and the process is called focused ultrasound assisted solvent extraction (FUASE) for distinguishing [55]. FUASE, compared to UASE, by some researchers is considered to be even more reproducible and faster, mainly due to a few times greater ultrasonic power [56].

Li et al. [57] investigated an ultrasound-assisted method for the extraction of 5-CQA from fresh leaves of du-zhong (Eucommia ulmoides Oliv). During experiments, the influence of four extraction variables (solvent type, its volume and concentration and extraction time) on the yield of 5-CQA was examined. As solvents, water, methanol, ethanol and isopropanol were tested. From the obtained results it was concluded that the mean extraction efficiency of 5-CQA decreases in the order: methanol $>$ ethanol $>$ water $>$ isopropanol. It was found that the aqueous methanolic mixture $(70 \%$ methanol in water, v/v) gives the highest extraction yield. An increase of extraction efficiency was also observed with the increase of the ratio of solvent volume to sample (the ratio of 20 was optimal) and the number of extraction cycles. It was proved that, in comparison to the conventional extraction techniques. triplicate extraction of 5-CQA for $30 \mathrm{~min}$ using each time fresh extractant reveals the highest 5-CQA yield. The optimized UASE process, by the same researchers, was applied for extraction of 5-CQA from fresh and dried bark of E. ulmodies and four other traditional Chinese medicines. It was turned out that independently of the plant matrix type the isolation efficiency of UASE was very high, and the obtained results highly reproducible.

\subsection{Microwave Assisted Solvent Extraction}

The microwave assisted solvent extraction (MASE) is considered as a novel method for isolation of CQAs from plants and related products using microwave heating. The principle of microwave heating, conversely to conventional heating, is based on direct absorption of microwave energy and its conversion into thermal energy, when the microwaves are passed through the medium $[58,59]$. The conversion of electromagnetic energy to heat occurs via two mechanisms, specifically, by dipole rotation and ionic conduction, i.e. by means of reversal of dipoles and displacement of charged ions present in the sample as well as in the solvent. Usually, these two mechanisms occur simultaneously, which 
effectively convert microwave energy into thermal one. Dipole rotation happens when the dipolar molecules attempt to follow the electric field in the same alignment. The induced oscillation leads to collisions between dipoles and surrounding molecules, and thus creates heat. Ionic conduction refers to the migration of ions under the influence of the electric field produced by microwaves. In this case the heat is generated due to the resistance of the medium to flow ions [58]. It should be added that in both mechanisms the generated thermal energy is immediately redistributed in the medium, which leads to homogeneous heating of the medium.

The MASE effectivity may be affected by a large variety of factors, such as frequency and power of microwaves, duration of microwaves irradiation, moisture content and particle size of plant samples, type and concentration of solvent, ratio of solid to liquid, extraction temperature and number of extraction cycles. Of these factors, solvent is regarded as one of the most important parameters, which affects the solubility of compounds and the absorption of microwaves energy. The higher the dielectric constant and dielectric loss, the higher is the solvent capacity to absorb microwave energy and the faster solvent heating. It should be added, however, that both polar and non-polar solvents can be used in MASE. Moreover, by combining solvents differing in their dielectric constant, the extractant properties and its selectivity can be modified. Nevertheless, the amount of water content in the extracted material and/or in solvent significantly influences the extraction yield [60].

In [61] the MASE applicability to CQAs extraction from green coffee beans was described. During these investigations, the influence of four extraction variables (solvent type, extraction time, extraction temperature and microwave power) on extraction efficiency of 5-CQA was tested. Among the examined solvents (ethanol, methanol and water), water proved to be the best extractant giving the highest yield of 5-CQA. It is due to the fact that the dielectric constant and polarity of water is higher than the alcohols. It was observed that extending the extraction time from 2 to 5 minutes resulted in the increased extraction efficiency. However, a further extension of the time resulted in a reduction of the 5-CQA yield. Taking into account the effect of extraction temperature on the total CQAs yield, it was shown that the highest yield was obtained at the temperature of $50^{\circ} \mathrm{C}$. Finally, testing the effect of microwave power it was noticed that the total CQAs yield was increased with the increase in microwave power up to $800 \mathrm{~W}$. Comparing the MASE results with those of the conventional extraction techniques, 
the authors concluded that the optimized MASE procedure equally effective isolates 5-CQA as the conventional techniques. The authors at the same time stressed that MASE reduced both time and solvent consumption. Therefore, MASE can be recognized as more environmentally friendly process providing high quality extracts rich in CQAs.

According to some researchers, the performance of MASE is highly influenced by the ratio of solid to liquid. A larger solvent volume can generally dissolve compounds of interest more effectively and lead to a higher extraction yield. As shown in [62] the extraction yield of 5-CQA from Eucommia ulmodies increased with the improvement of the solvent volume (i.e. the reduction of the ratio of solid to liquid). The 5-CQA yield increased steadily when the plant mass was kept constant and the liquid volume was raised. That is to say, extraction yield of plant constituents is most likely depending on how ratio of solid to liquid is regulated. Therefore, in MASE the plant sample extraction is typically conducted in multiple steps, using the consecutive extraction cycles with fresh portion of the extractant. This practice helps to improve the extraction yield and prevents prolonged heating of the sample in the same solvent volume. In addition, the use of fresh portions of extractant prevents the saturation of the solvent with analytes, increasing their mass transfer and extraction kinetics [63]. In other words, MASE can extract compounds more rapidly, thus the heat-sensitive compounds are shortly exposed to potentially harmful conditions and in consequence their yields can be higher in comparison to those obtained by the conventional extraction methods.

\subsection{Pressurized Liquid Extraction}

Pressurized liquid extraction (PLE), also known as accelerated solvent extraction (ASE), pressurized solvent extraction (PSE), enhanced solvent extraction (ESE), pressurized hot water extraction (PHWE), subcritical water extraction or superheated water extraction (SWE), has gained popularity due to its lower solvent consumption and significantly shorter extraction times required for complete isolation of bioactive compounds from plants. In this technique samples are enclosed in stainless steel extraction cells and extracted with solvents at high pressure and temperatures $\left(50-200^{\circ} \mathrm{C}\right)$. The use of elevated pressures and temperatures enhances the extraction yield compared to the conventional extraction methods by increasing the solubility and mass transfer effects and, also decreasing the viscosity and surface tension of solvents. PLE has proven to be an equivalent or superior alternative for the extraction of different analytes from various matrices [64-66]. In comparison to the 
conventional techniques PLE was found to dramatically decrease time consumption and solvent use and, due to this fact the technique is frequently described as a green extraction technique [67]. For isolation of polar compounds PLE is also considered as a potential alternative technique to supercritical fluid extraction [59].

Alonso-Salces et al. [68] optimized PLE for determination of phenolic compounds in Golden Delicious apple peel and pulp taking into account the effect of experimental variables, such as solvent composition, extraction temperature, static extraction time and pressure. According to presented results, the extraction yield increased with the percentage of methanol in the extraction mixture. The most powerful extraction mixture was $60 \%$ solution of methanol in water. As to the effect of extraction temperature, it was observed that up to $60^{\circ} \mathrm{C}$ the extraction yield first slightly increases and then falls down with a further increase in the temperature. Besides, it was found that the temperature increase leads to obtain cloudy extracts. Therefore, even if the extraction at $60^{\circ} \mathrm{C}$ provided the highest phenolics yield, $40^{\circ} \mathrm{C}$ was chosen as the optimum temperature. Studying the static extraction time $(5,10$ and $15 \mathrm{~min})$, it was observed that the amounts of extracted analytes were practically constant during these periods of time. When the extraction pressure was examined (1000, 1250 and 1500 p.s.i.), any significant influence on the efficiency of the process was detected. The same effect has been reported by others authors [69], because of the fact that the purpose of pressurizing the extraction cell is to prevent the solvent from boiling at the extraction temperature and to ensure that the solvent remains in intimate contact with the sample. In addition to the PLE parameters such as solvent type, temperature and static extraction time, Luthria [70] showed that particle size, flush volume and solid-to-liquid ratio also influence the extraction yield of phenolics from parsley (Petroselinum crispum) flakes. Erdogan et al. [71] 5-CQA recovered from various parts of Anatolia propolis using $\mathrm{PLE}$ at $40^{\circ} \mathrm{C}, 1500 \mathrm{psi}$ for $15 \mathrm{~min}$.

\section{CHLOROGENIC ACIDS ANALYSIS}

There are many analytical methods to identify and quantify chlorogenic acids in natural samples $[3,4,14-17,19,26,30,32,33,36$, 37, 39-50, 55, 57, 62, 66, 68-108]. According to our knowledge, however, there is no official and universally accepted methods of CQAs analysis. Therefore many laboratories develop and validate their own 
analysis methods. All the more that depending on the analytical technique chosen different approaches to sample preparation may be considered and, as it was stated before, nowadays there is a tendency to replace the conventional extraction techniques by newer and more effective processes. It should be also remembered that even when using the same analytical technique, different equipment and different its settings can be selected. The fact that CQAs constitute a large family of compounds with various properties present in natural samples on different concentration levels additionally makes their analysis more difficult. Hence, frequently, in the course of single run, only a few CQAs representatives with very similar properties are analyzed, for example monoCQAs or diCQAs, and even an individual compound i.e. 5-CQA is subjected to analysis. Yet, due to the application of modern highly selective, sensitive and accurate analytical techniques this trend begins to slowly change in direction of analysis large numbers of CQAs in one single run. Examples of currently applied methods of CQAs analysis are summarized in Table 1.

According to the literature study $[3,4,14-17,19,20-26,30,32,33$, $36,37,39-50,55,57,61,66,68-108]$ and data presented in Table 1, it can be concluded that liquid chromatography (LC) and capillary electrophoresis (CE) with different detection systems are the most commonly applied.

\subsection{Electrophoretic analysis}

Guan et al. [88] developed a method based on capillary electrophoresis with electrochemical detection (CE-ED) to determine 5-CQA in sweet potato. In this method the laboratory-built CE-ED system was used. A $+30 \mathrm{kV}$ high-voltage power supply provided a separation voltage between the ends of the capillary. The inlet end of the capillary was held at a positive potential, and the outlet end was maintained at ground. All samples were injected electrokinetically, applying $18 \mathrm{kV}$ for $6 \mathrm{~s}$. A threeelectrode cell system consisting of a carbon-disk working electrode, a platinum auxiliary electrode, and a SCE (saturated calomel electrode) reference electrode was used in combination with ampere-metric detector. By the migration time of the analyte as compared with electropherogram of the standard solution, the active ingredient in sweet potato samples can be identified and quantitatively determined. The results obtained by Guan 


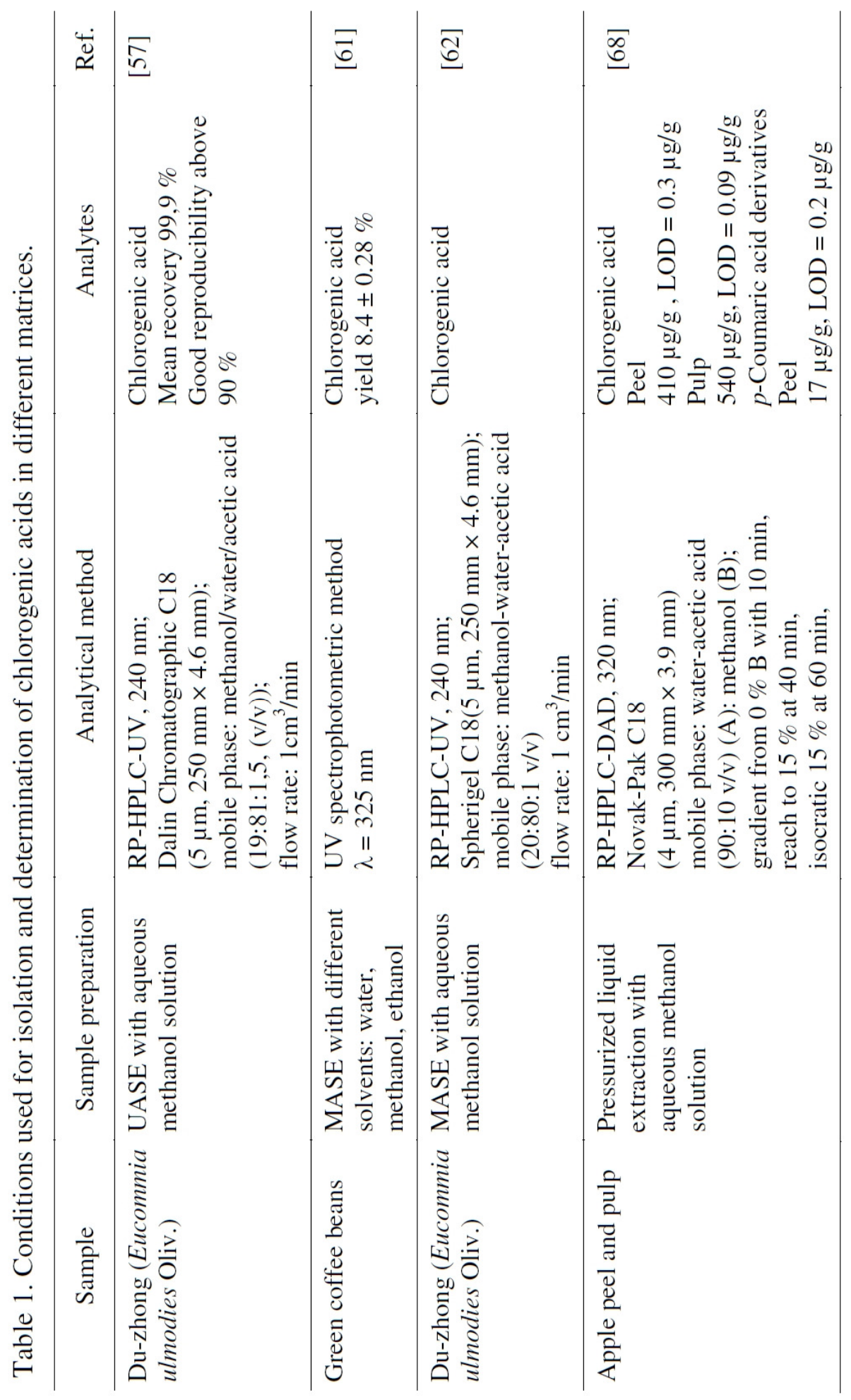




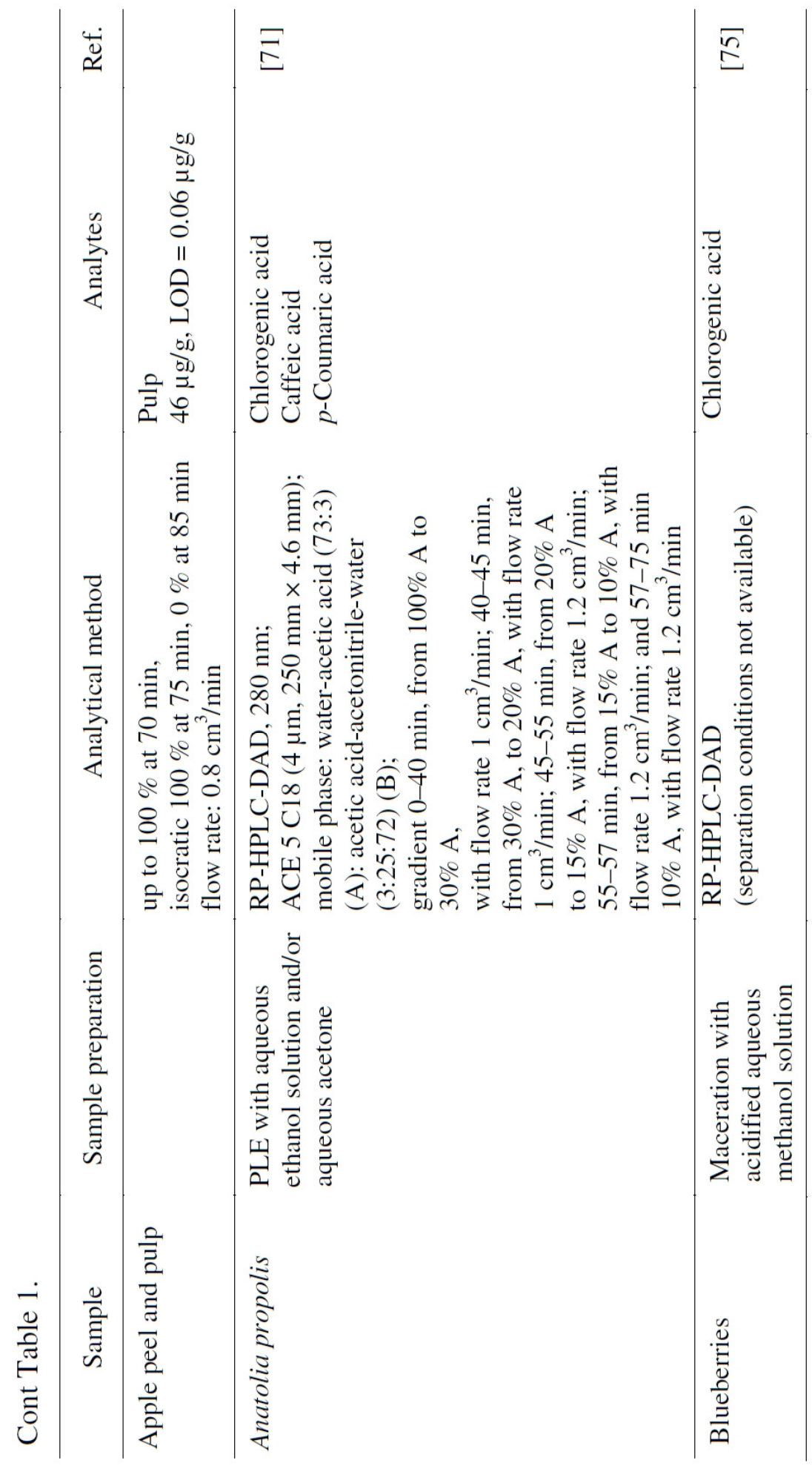




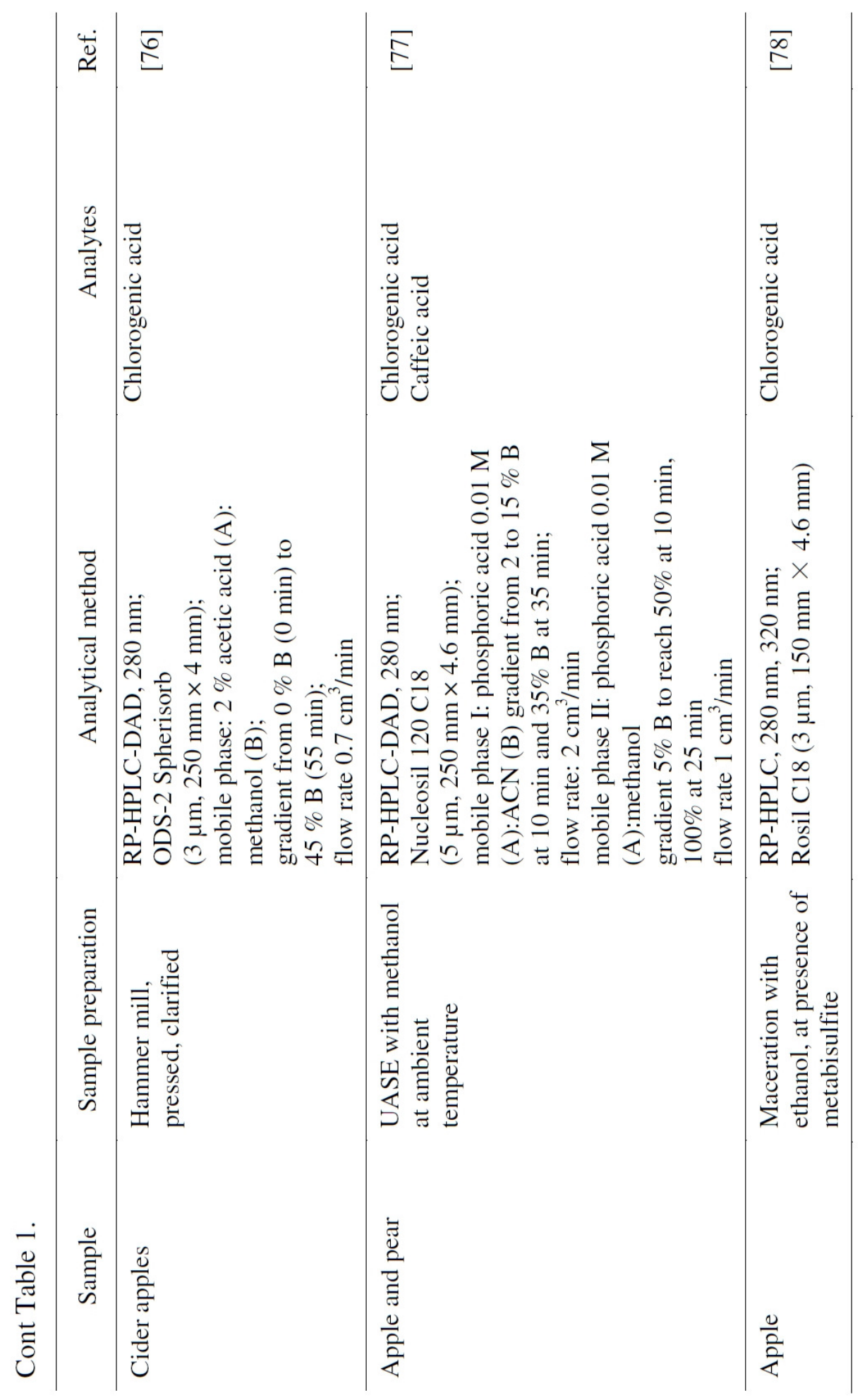




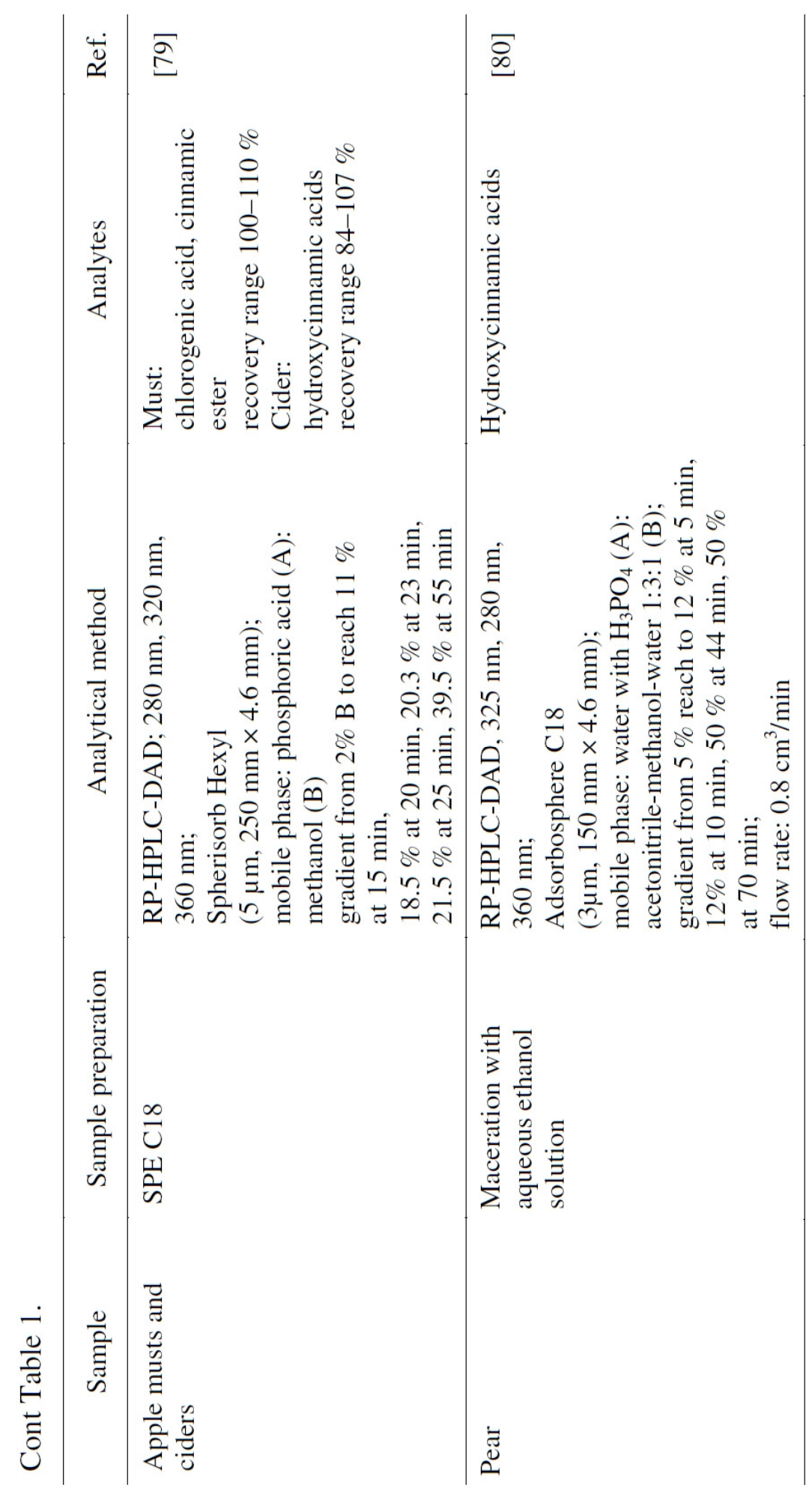




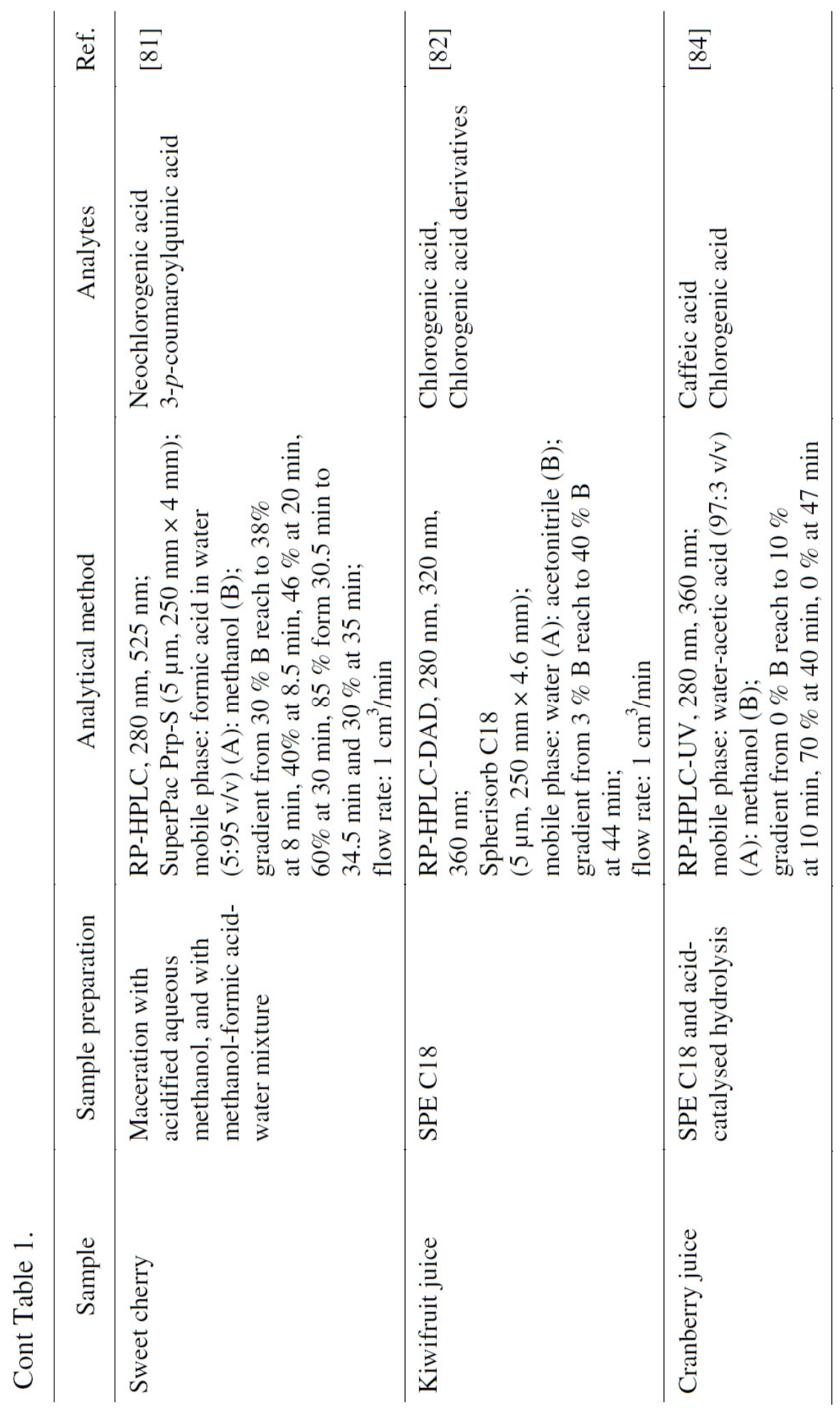




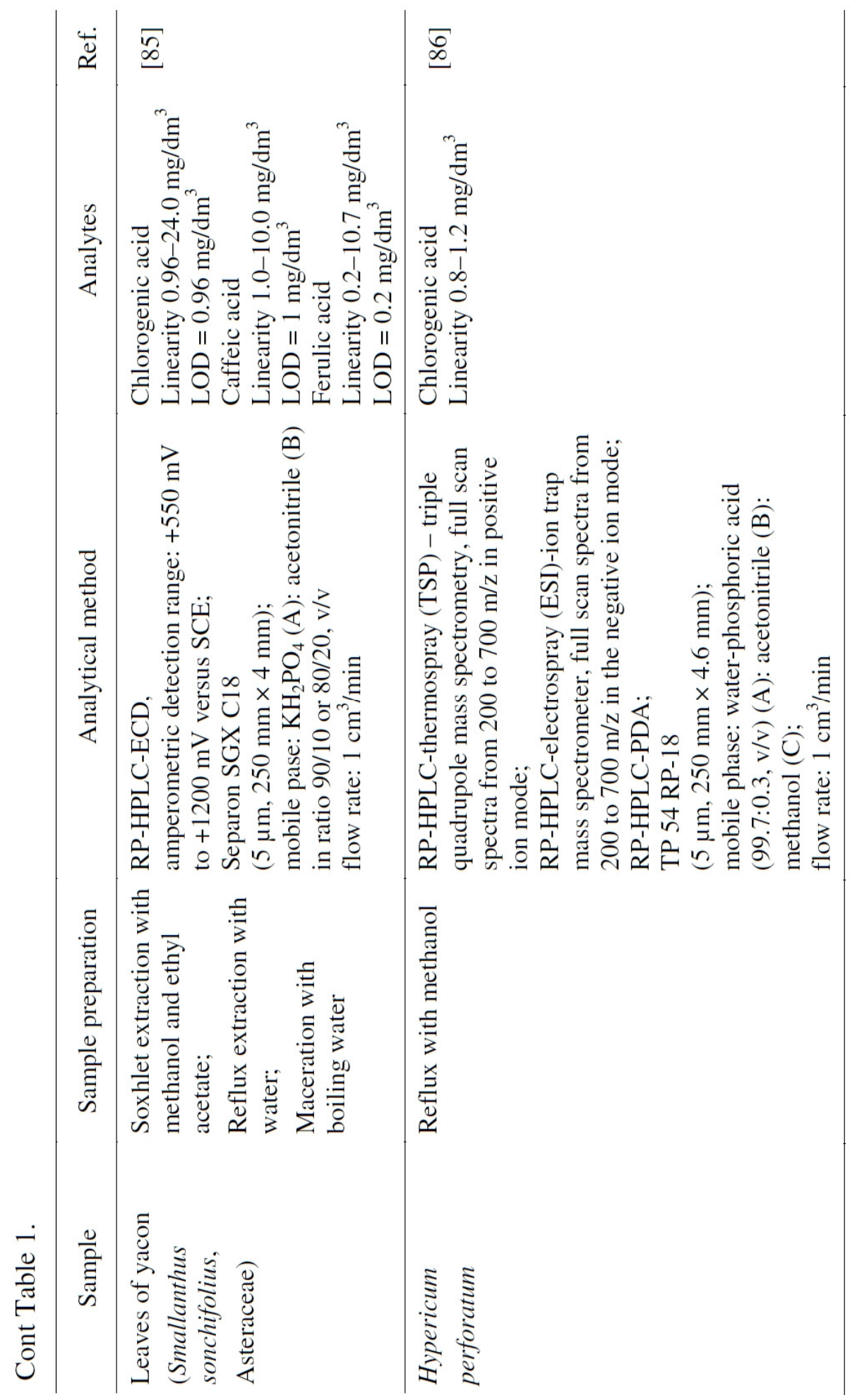




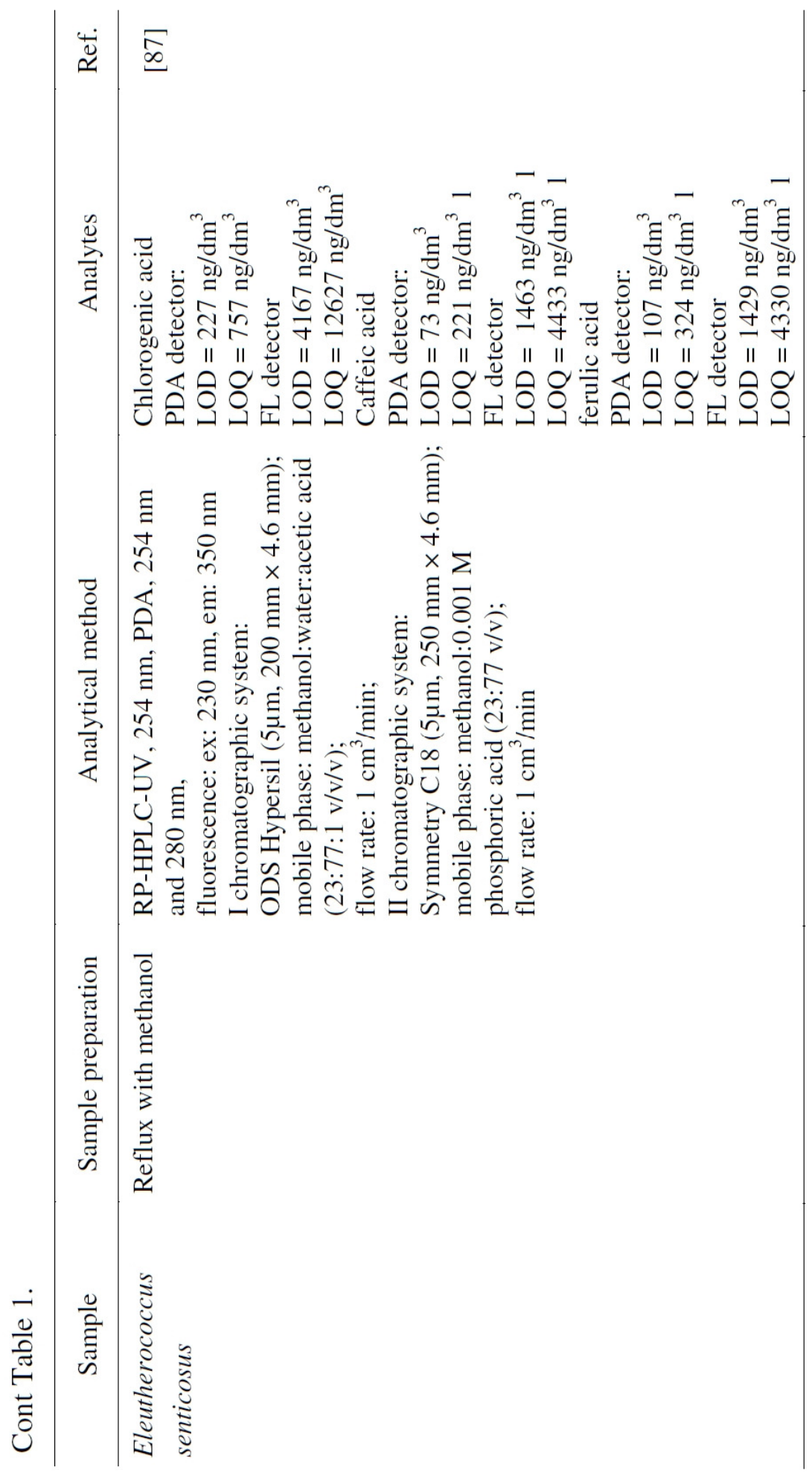




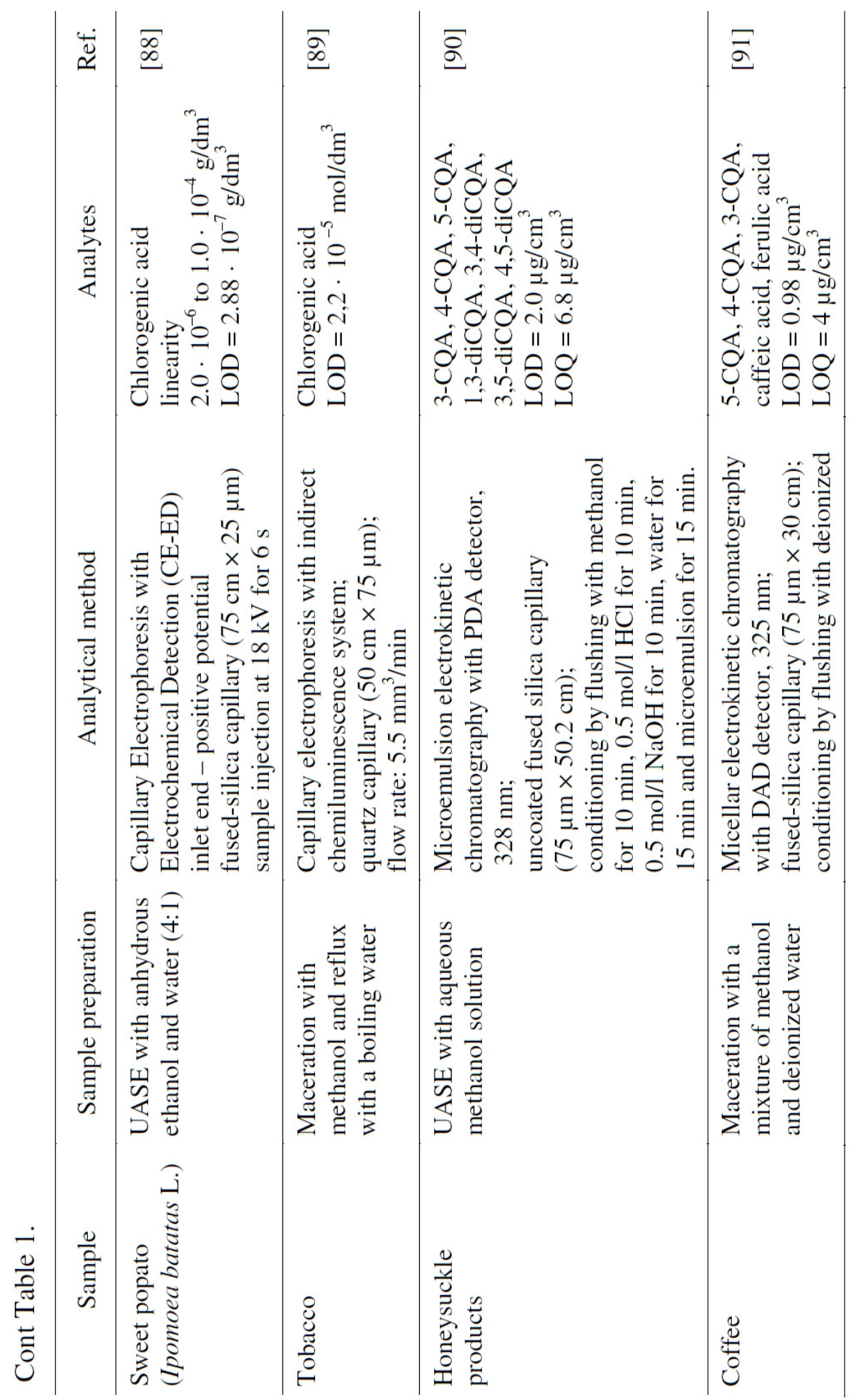




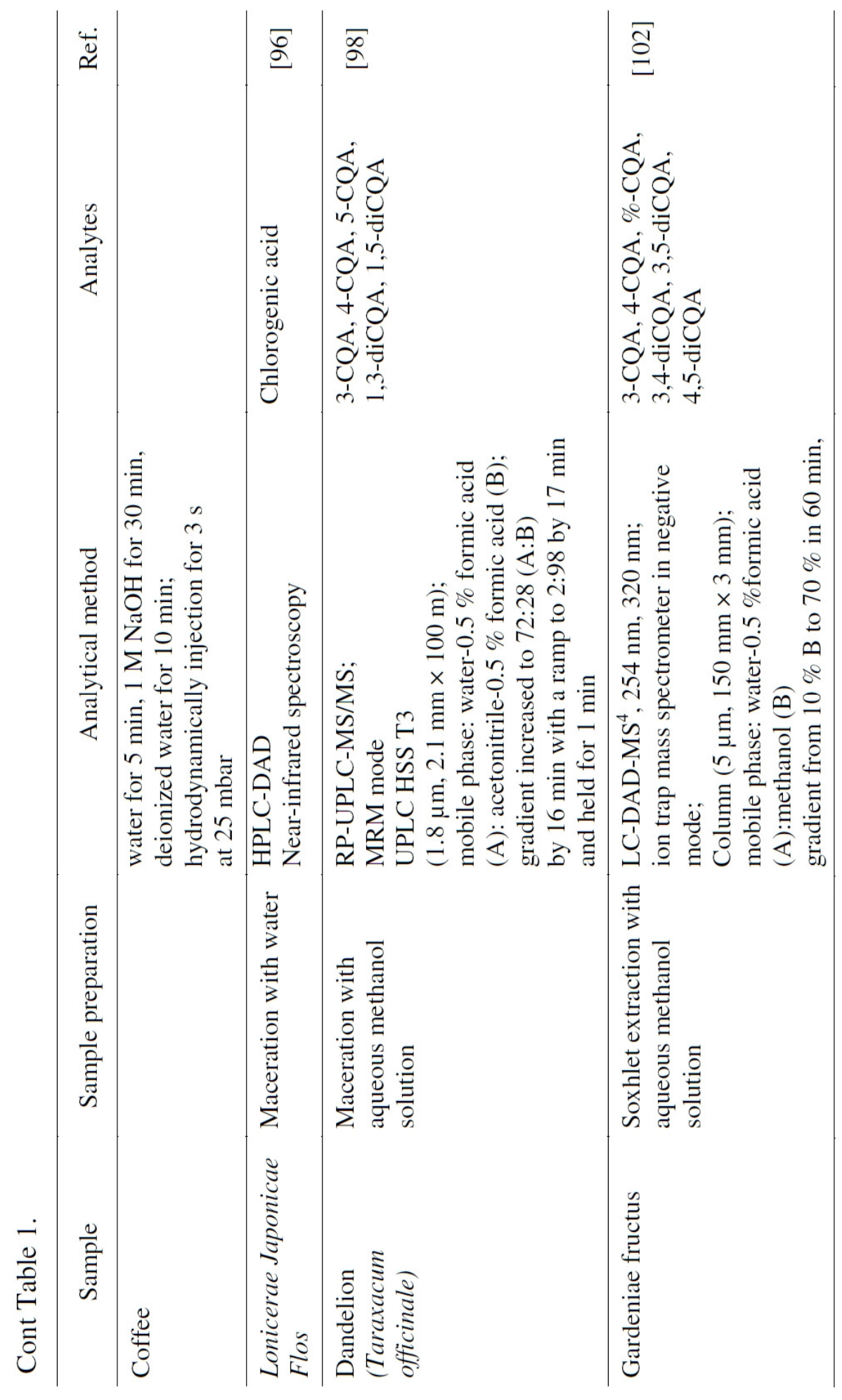




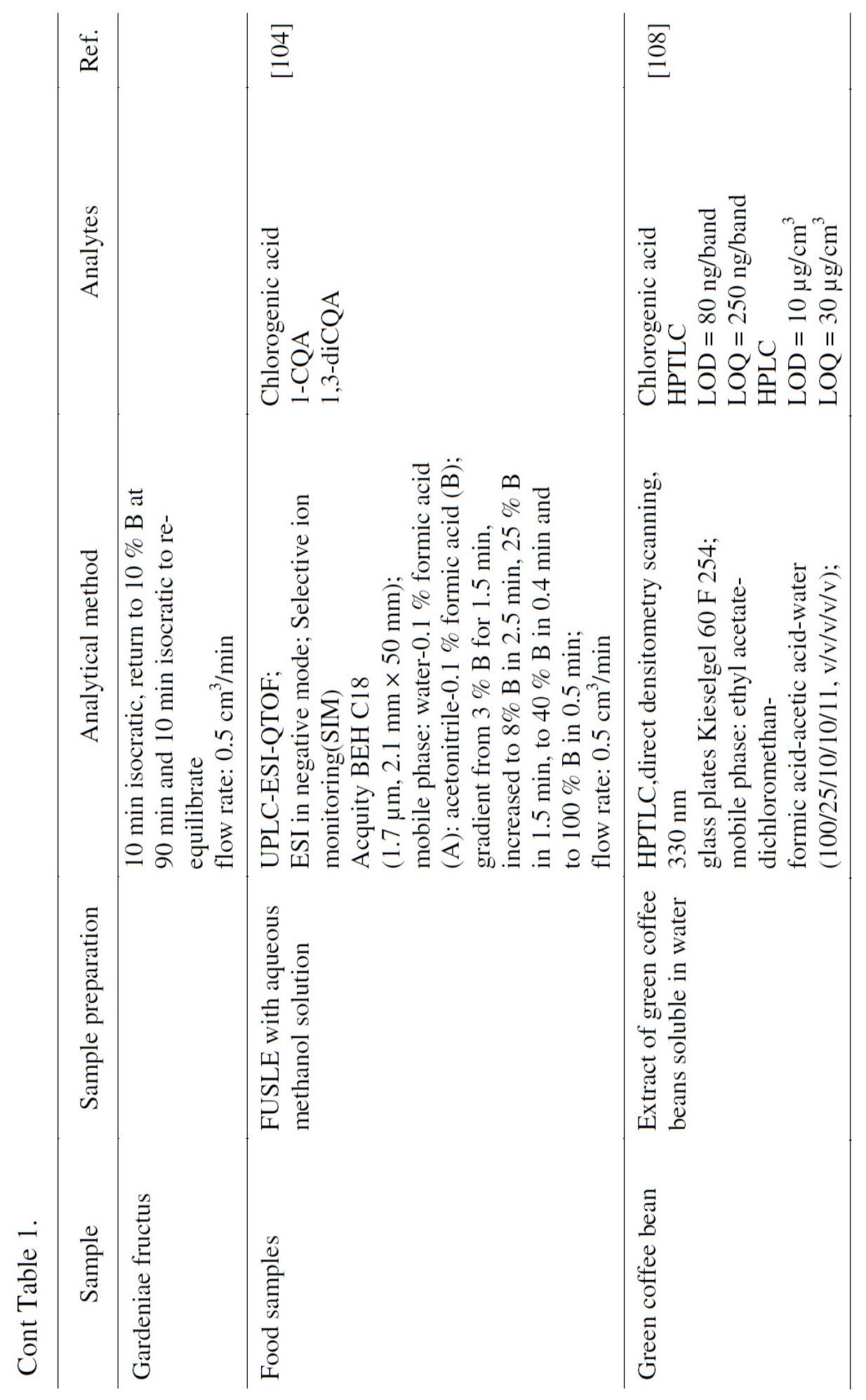




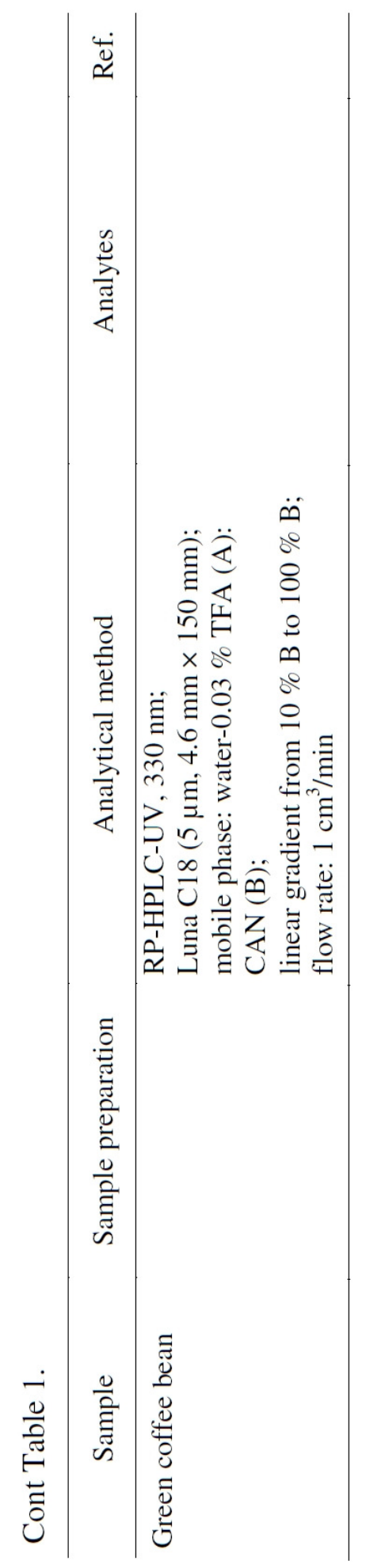


et al. [88] indicate that CE-ED is accurate, sensitive, and useful method for the quantitation of 5-CQA in sweet potato.

Jiang et al. [89] employed an improved capillary electrophoresis procedure for the determination of chlorogenic acid in tobacco samples. In the procedure, the analyte zone, after being separated by capillary electrophoresis, it was determined by indirect chemiluminescence of luminol-potassium hexacyanoferrate. In this system, luminal was added into running buffer solution and introduced at the head of separation quartz capillary, and potassium hexacyanoferrate was introduced at the end of capillary. 5-CQA in the samples was determined quantitatively by the calibration of standard addition method and the correction of matrix background signal. According to the authors, the proposed capillary electrophoresis-chemiluminescence system can avoid the electrolysis of chemiluminescence reagent, retain the stability of chemiluminescence baseline and prolong the working time of running and electrode buffer solutions.

A special mode of capillary electrophoresis employing a microemulsion as carrier electrolyte, so-called microemulsion electrokinetic chromatography (MEEKC) method, in which analytes may partition between the aqueous phase of microemulsion and its oil droplets acting as a pseudostationary phase, was employed by Tang et al. [90] for the simultaneous determination of seven CQAs acids in honeysuckle - related products. The proposed MEEKC procedure with PDA detection at $328 \mathrm{~nm}$, with the addition of tartrate for improving separation efficiency, was sufficient for separation and quantification of three monoCQAs and of four diCQAs within $22 \mathrm{~min}$. Citing the authors of the report, the method proposed by them can be extensively used to determine individual CQA isomers in honeysuckle or its preparations, and can provide more references for the quality evaluation and control of CQA related products.

Another modification of capillary electrophoresis i.e. micellar electrokinetic chromatography (MEKC), in which samples are separated by differential partitioning between micelles (pseudostationary phase) and a surrounding aqueous buffer solution acting as mobile phase, was proposed by Risso et al. [91] for separation of CQAs in coffee. The electrophoretic conditions consisted of an sodium dodecyl sulphate (SDS) (70 mM)-phosphate $(17.6 \mathrm{mM})$-methanol $(5 \%, \mathrm{v} / \mathrm{v})$ buffer system, $\mathrm{pH}=2.5,22.1^{\circ} \mathrm{C},-17 \mathrm{kV}$ and detection at $235 \mathrm{~nm}$. The separations were carried out on a fused-silica capillary with effective and total length of $22.5 \mathrm{~cm}$ and $30 \mathrm{~cm}$, respectively. The method was tested both with green 
and roasted coffee beans, and in both cases it was proved to be effective and selective. According to the authors of the paper, the method can be used to monitor the presence of mono-CQA isomers in natural as well as processed vegetables.

\subsection{Chromatographic analysis}

Numerous papers have been published in qualitative and quantitative analysis of CQAs in plants by liquid chromatography (LC) coupled with spectroscopic detection techniques, such as ultraviolet (UV), fluorescence (FL) nuclear magnetic resonance (NMR) and mass spectroscopy (MS), and even near-infrared (NIR) spectroscopy [56, 61,62, 84, 86, 87, 89, 9299]. It is worth to add that nowadays the coupling of separation and detection techniques can involve more than one separation or detection techniques, e.g. LC-UV-MS, LC-MS-MS, LC-NMR-MS, and the like [14, 16, 47, 99-101, 102]. For example, a simple LC-DAD/ESI-MS ${ }^{\mathrm{n}}$ method has been used by Gouveia and Castilho [103] for the screening of various phenolic compounds, including CQAs, in Helichrysum devium extracts. On the other hand, where CQAs are present on low concentration levels and their precise analysis is essential, on-line coupling with the CQAs extraction can be incorporated to build in a more integrated and sophisticated system e.g. FUSLE-LC-MS [104].

High-performance liquid chromatography (HPLC) is still the most widely used analytical separation technique. Though, the more advanced form of LC i.e. ultra-performance liquid chromatography (UPLC) becomes increasingly popular in the determination of plant extracts compounds, due to the improved resolution, shorter retention times and higher sensitivity [55, 104-106]. In general, LC separations of CQAs are performed by reversed phase system. The commonly applied stationary phases are based on $\mathrm{C} 18$ [3, 16, 17, 26, 30, 36, 40, 44, 46-48, 50, 55, 57, $68,71,76-78,80,86,105]$. The mobile phase consists of mixtures of methanol-water $[14,47-50,57,62,68,76,79,81,84,87]$, and acetonitrile-water [15-17, 30, 36, 40, 41, 44, 46, 55, 71, 77, 82, 98, 104]. Detectors used to monitor CQAs separations are diode array detectors (DAD) or photodiode array detectors (PDA). It should be remembered, however, that only a few CQAs standards are available commercially, and the precise analysis of the individual CQAs by means of conventional LC-DAD(PDA) systems is not easy. Hence, nowadays the use of MS and tandem MS is preferred by most laboratories because of their higher selectivity and sensitivity. In order to improve the ionization capacity of CQAs in MS, formic acid at a concentration level of $0.1 \%$ is frequently 
added to the mobile phase $[14-16,30,36,40,41,47-50,55,81,98,102$, 104, 108]. Ionization is usually performed by electrospray ionization (ESI) working in negative mode [14-16, 36, 40, 41, 46, 49, 50, 55, 86, 98, 99, 100, 102, 104, 105]. The most common MS analysers in LC-based methods for CQAs analysis in plants are ion trap (IP), triple quadrupole (TQD) and time of flight (TOF) [14-17, 36, 40, 41, 47-49, 55, 86, 99, $104,105,107]$. Tandem MS gives the possibility of measuring in selected reaction monitoring (SRM), which is a very selective acquisition mode. Typically 2 or 3 SRM transitions are selected for target analysis of CQAs: one for quantification and an additional one for confirmation purposes.

Urakova et al. [108] developed and compared two LC methods, high-performance thin-layer chromatography (HPTLC) and HPLC, for separation and quantitative determination of 5-CQA in green coffee bean extracts. HPTLC analysis were performed on glass plates Kieselgel $60 \mathrm{~F} 254$ (Merck) using densitometric determination at $330 \mathrm{~nm}$. HPLC separations were achieved using a Luna C18 column. Data showed the absence of statistically significant differences for HPTLC and HPLC results. Thus, according to the authors, the HPTLC-densitometric method could be used for the quantitative determination of 5-CQA in extracts as an alternative to HPLC in rapid screening or in routine analysis.

The quantification of a series of related caffeoylquinic acid derivatives was carried out using UPLC-MS-MS [107]. In this method a liquid chromatograph was coupled to TQD mass spectrometer via ESI as the ion source working in negative mode. Detection of CQAs was conducted in multiple reaction monitoring (MRM) mode by analysis two transition ions per compound. In the report it was proved that this hyphenated technique offers a number of distinct advantages over conventional HPLC systems for the separations and identification of isomeric compounds. Additionally TQD, applied in the system, allows for more definite identification and indeed quantification of individual compounds based on their molecular mass and MS/MS fragmentation.

Clifford M. et al. [102] investigated qualitatively the chlorogenic acids of Gardeniae Fructus by liquid chromatography/multi-stage mass spectrometry $\left(\mathrm{LC} / \mathrm{MS}^{4}\right)$. Using this method it has been possible to discriminate between individual isomers of mono-, di- and triCQAs without the need to isolate the pure compounds. In the applied system, a LC chromatograph with DAD was interfaced with an ion-trap mass spectrometer fitted with an ESI source operating in full scan. $\mathrm{MS}^{2}, \mathrm{MS}^{3}$ and $\mathrm{MS}^{4}$ fragment-targeted experiments were performed to focus only on compounds producing a precursor ion at $\mathrm{m} / \mathrm{z}, 335,397,497,511,543$, 
$559,573,659$, and 673. In the report, twenty-nine chlorogenic acids were detected and twenty-five characterized to regioisomer level on the basis of their fragmentation, twenty-four for the first time from this source. Fourteen of these twenty-nine chlorogenic acids have not previously been reported from any source.

Tena et al. [104], to determine CQAs in feed and related products, used for the first time focused ultrasound solid-liquid extraction (FULSE) followed by UPLC-PDA coupled to quadrupole-time of flight (Q-TOF) mass spectrometry. As before, electrospray ionization was operated in negative mode. Wavelength values of 329 and $325 \mathrm{~nm}$ were selected to record the UV chromatograms of 5-CQA and 1,3-diCQA, respectively. According to the presented results, the method allows an efficient determination of CQAs with good recovery rates. Therefore, citing the authors, the method may be used for screening of raw material and for process and quality control in feed manufacture.

Xiao et al. [96] developed a rapid quantitative analytical method for the determination of three components (secologanic acid, chlorogenic acid and galuteolin) in the Lonicerae Japonicae Flos extracts using nearinfrared (NIR) spectroscopy. The concentrations of analytes were determined by using HPLC-DAD as the reference method. A gradient elution HPLC method was established. The NIR spectra of the samples were obtained at 1-nm intervals over the spectral region from 1000 to $2500 \mathrm{~nm}$ using a SupNIR-4510 instrument. Each spectrum was obtained by averaging 16 scans. The useful bands of NIR ranged from 1000 to $2500 \mathrm{~nm}$, which correspond to the first or second overtone. The intensity of NIR absorption decreases as the overtone increases. NIR spectroscopy can be used in manufacturing industry because of the stable, feasible and ascendant model established.

Finally, the less frequently applied chromatographic techniques must be mentioned. One of them is centrifugal partition chromatography (CPC). This technique, like other countercurrent chromatography techniques, is based on the phenomenon of liquid-liquid partitioning between two immiscible liquid phases that stay at equilibrium. But the significant difference between this technique and others is the retention mechanism of stationary phase. In the case of CPC, this mechanism is based on hydrostatic force, formed by the centrifugal field in the rotor in one-axis centrifuge. CPC was applied by Kim et al. [109] for preparative isolation of 5-CQA from highbush blueberry leaves (Vaccinium corymbosum L.). A water fraction containing a high concentration of 5-CQA $(14.5 \%$ of dry weight extract) was obtained by defatting a crude methanol extract 
from blueberry leaves. To isolate 5-CQA from this water fraction a twophase solvent system of ethyl acetate-ethanol-water at a volume ratio 4:1:5 (v/v/v) was applied. HPLC, UV, ESI/MS and NMR spectra were used to confirm the structure of 5-CQA in the CPC fraction. The HPLC chromatogram showed that the fractions collected by CPC contained 5-CQA acid with $96 \%$ purity based on peak area percentage. The total amount of chlorogenic acid isolated from $0.5 \mathrm{~g}$ of a water fraction was $52.9 \mathrm{mg}$, corresponding to $10.6 \%$ of the water fraction.

\section{CONCLUSIONS}

The objective of this review is to give an overview of the occurrence, properties, and methods that have been developed to improve the extraction and analysis of chlorogenic acids in plants and related products, with special attention to 5-O-caffeoylquinic acid and 1,3-di-Ocaffeoylquinic acid as these compounds of the chlorogenic acids family with many beneficial health effects. It is because of the potential biological activity of these compounds, recently, there has been an increased interest in natural products rich in chlorogenic acids. Consequently, more efficient extraction methods, leading to obtain extracts with enhanced CQAs content and reduced content of their degradation products, are being sought. On the other hand, taking into account the application of CQAs as pharmaceutical and food additives and their properties, more efficient and reliable analytical methods are constantly sought after.

In the last few years, a number of improvements in the strategy of extraction and analysis of CQAs in different natural samples have been achieved. The application of newer, faster, more efficient and sophisticated extraction techniques, such as UASE, MASE or PLE, has significantly improved the extraction yield of CGAs with a significant reduction of organic solvents consumption. The overall quality of the extracts has also been improved. In addition, this has resulted in a reduction of the manipulation errors, and in consequence it has led to improved reproducibility and repeatability of the analytical methods.

There is no official and universally accepted methods of CQAs analysis in plants and related products. The large number of compounds belonging to CQAs family and the fact that these methods need to be applicable to many various plants make this wish hard to accomplish. Nevertheless, nowadays two analytical techniques commonly applied for 
the analytical separation of CQAs can be distinguished. It is capillary electrophoresis and liquid chromatography. The latter, especially when is coupled to a tandem MS/MS, it can be even considered as the technique that occupies the leading position for the analysis of compounds belonging to CQAs family.

\section{REFERENCES}

[1] M.N. Clifford. Review: Chlorogenic acids and other cinnamates-nature, occurrence and dietary burden. Journal of the Science of Food and Agriculture, 79:326-372 (1999).

[2] M.N. Clifford. Review - Chlorogenic acids and other cinnamates nature, occurrence, dietary burden, absorption and metabolism. Journal of the Science of Food and Agriculture, 80:1033-1043 (2000).

[3] A. Farah, T. De Paulis, L.C. Trugo, P.R Martin. Effect of roasting on the formation of chlorogenic acid lactones in coffee. Journal of Agriculture and Food Chemistry, 53:1505-1513 (2005).

[4] M.H.Kweon, H.J. Hwang, H.C. Sung. Identification and antioxidant activity of novel chlorogenic acid derivatives from bamboo (Phyllostachys edulis). Journal of Agriculture and Food Chemistry, 49:4646-4655 (2001).

[5] W.E. Robinson, M.G. Reinecke, S. Abdel-Malek, Q. Jia, S.A. Chow. Inhibitors of HIV-1 replication that inhibit HPV integrase. Proceedings of the National Academy of Science U.S.A., 93:6326-6331 (1996).

[6] H.C. Kwon, C.M.Jung, C.G. Shin, J.K. Lee, S.U. Choi, S.Y. Kim, K.R Lee. A new caffeoyl quinic acid from Aster scaber and its inhibitory activity against human immunodeficiency virus-1 (HIV-1) integrase. Chemical and Pharmaceutical Bulletin, 48:1796-1798 (2000).

[7] L.A. Ludwig, M.N. Clifford, M.E.J. Lean, H. Ashihara, A. Crozier. Coffee: biochemistry and potential impact on health, Food and Function, 5:1695-1717 (2014).

[8] T. Tanaka, T. Kojima, T. Kawamori, A. Wang, M. Suzui, K. Okamoto, $\mathrm{H}$. Mori, Inhibition of 4-nitro-quinoline-1-oxide-induced rat tongue carcinogenesis by the naturally occurring plant phenolics caffeic, ellagic, chlorogenic, and ferulic acids. Carcinogenesis, 14:1321-1325 (1993).

[9] M. Ohnish, H. Morishita, H. Iwahashi, S. Toda, Y. Shirataki, M. Kimura, R. Kido. Inhibitory effects of chlorogenic acids on linoleic acid peroxidation and hemolytic. Phytochemistry, 36:579-583 (1994).

[10] H. Kasai, Z. Fukada, S. Yamaizumi, S. Sugie, H. Mori. Action of chlorogenic acid in vegetables and fruits as an inhibitor of 8hydroxydeoxyguanosine formation in vitro and in a rat carcinogenesis model. Food and Chemical Toxicology, 38:467-471 (2000). 
[11] K.L. Johnston, M.N. Clifford, L.M. Morgan. Coffee acutely modifies gastrointestinal hormone secretion and glucose tolerance in humans: glycemic effects of chlorogenic acid and caffeine. The American Journal of Clinical Nutrition, 78:728-733 (2003).

[12] H. Hemmerle, H. Burger, P. Below, G. Schubert, R. Rippel, P.W. Schindler, E. Paulus, A.W. Herling. Chlorogenic acid and synthetic chlorogenic acid derivatives: novel inhibitors of hepatic glucose-6-phosphate translocase. Journal of Medicinal Chemistry, 40:137-145 (1997).

[13] J. Shearer, A. Farah, T. de Paulis, D.P .Bracy, R.R. Pencek, T.E. Graham. Quinides of roasted coffee enhance insulin action in conscious rats. Journal of Nutrition, 133:3529-3532 (2003).

[14] R. Jaiswal, M.F. Matei, A. Golon, M. Witt, N. Kuhnert. Understanding the fate of chlorogenic acids in coffee roasting using mass spectrometry based targeted and non-targeted analytical strategies. Food and Function, 3:976-984 (2012).

[15] A.L. Dawidowicz, R. Typek. Thermal Stability of 5-O-Caffeoylquinic Acid in Aqueous Solutions at Different Heating Conditions. Journal of Agricultural and Food Chemistry, 58:12578-12584 (2010).

[16] A.L. Dawidowicz, R.. Typek. Transformation of chlorogenic acids during the coffee beans roasting process. European Food Research \& Technology, 243:379-390 (2017).

[17] K. Schutz, D. Kammerer, R. Carle, A. Schieber. Identification and Quantification of Caffeoylquinic Acids and Flavonoids from Artichoke (Cynara scolymus L.) Heads, Juice, and Pomace by HPLC-DADESI/MS ${ }^{\mathrm{n}}$. Journal of Agricultural and Food Chemistry, 52:4090-4096 (2004).

[18] Kim, H. Kim, W.L. Kerr, S. Choi. The effect of grinding at various vacuum levels on the color, phenolics, and antioxidant properties of apple. Food Chemistry, 216:234-242 (2017).

[19] H.D. Mosel, K. Herrmann. The contents of catechins and hydroxycinnamic acids in pome and stone fruits. Z Lebensm Unters Forsch, 154:6-11 (1974).

[20] G.A. Spanos, R.E. Wrolstad. Phenolics of apple, pear, and white grape juices and their changes with processing and storage - a review. Journal of Agricultural and Food Chemistry, 40:1478-1487 (1992).

[21] B. Risch, K . Herrmann. Die Gehalte an HydroxyzimtsaureVerbindungenund Catechinen in Kernund Steinobst. Z Lebensm Unters Forsch, 186:225-230 (1988).

[22] Y. Lu, Y. Foo. Identification and quantification of major polyphenols in apple pomace. Food Chemistry, 59:187-194 (1997).

[23] S. Burda, W. Oleszek, C.Y. Lee. Phenolic compounds and their changes in apples during maturation and cold storage. Journal of Agricultural and Food Chemistry, 38:945-948 (1998). 
[24] G. Ritter, U. Hagenauer-Hener, H. Dietrich. The phenolic substances of Sorbus domestica $\mathrm{L}$ and their importance for the quality of apple wines, in Polyphenols 94. XVIIe Journees Internationales Groupe Polyphenols, Ed by R. Brouillard, M. Jay, A. Scalbert, INRA Editions, Paris, France, 235-236 (1995).

[25] A.G. Malmberg, O. Theander. Free and conjugated phenolic acids and aldehydes in potato tubers. Swedish Journal of Agricultural Research, 14:119-125 (1984).

[26] A.G. Malmberg, O. Theander Determination of chlorogenic acid in potato tubers. Journal of Agricultural Food and Chemistry, 33:549-551 (1985).

[27] S.N. Onyencho, N.S. Hettiarachchy. Antioxidant activity, fatty acids and phenolic acids composition of potato peels. Journal of the Science of Food and Agricultural, 62:345-350 (1993).

[28] M.N. Clifford, R. Walker. Letter to the editor: Chlorogenic acids confounders of coffee-serum cholesterol relationship. Food Chemistry, 24:77-80 (1987).

[29] W. Boerjan, J. Ralph, M. Baucher. Lignin biosynthesis. Annual Review of Plant Biology, 54:519-546 (2003).

[30] Furrer, D.P. Cladis, A. Kurilich, R. Manoharan, M.G. Ferruzzi. Changes in phenolic content of commercial potato varieties through industrial processing and fresh preparation. Food Chemistry, 218:47-55 (2017).

[31] V. Lattanzio, P.A Kroon, V. Linsalata, A. Cardinali. Globe Artichoke: A functional food and source of nutraceutical ingredients. Journal of Functional Foods, 1:131-144 (2009).

[32] V. Lattanzio, I. Morone. Variations of the orthodiphenol content in Cynara scolymus L. during the plant growing season. Experientia, 35:993-994 (1979).

[33] V. Lattanzio, C.F. Van Sumere. Changes in phenolic compounds during the development and cold storage of artichoke (Cynara scolymus L.) heads. Food Chemistry, 24:37-50 (1987).

[34] V. Lattanzio, N. Cicco, V. Linsalata. Antioxidant activities of artichoke phenolics. Acta Horticulturae, 681:421-428 (2005).

[35] R. Upadhyay, L.J.M. Rao. An Outlook on Chlorogenic Acids Occurrence, Chemistry, Technology, and Biological Activities. Critical Reviews in Food Science and Nutrition, 53: 968-984 (2013).

[36] I.M. Abu-Reidah, D. Arraez-Roman, A. Segura-Carretero, A. FernandezGutierrez. Extensive characterization of bioactive phenolic constituents from globe artichoke (Cynara scolymus L.) by HPLC-DAD-ESI-QTOFMS. Food Chemistry, 141:2269-2277 (2013).

[37] M.N. Clifford, R.J. Ramirez-Martinez. Chlorogenic acids and purine alkaloid content of Mate (Ilex paraguariensis) leaf and beverage. Food Chemistry, 35:13-21 (1990). 
[38] P. Mazzafera. Mate drinking: caffeine and phenolic acid intake. Food Chemistry, 60:67-71 (1997).

[39] M.I. Dias, L. Barros, M. Duenas, E. Pereira, A.M. Carvalho, R.C. Alves, M.B.P.P. Oliveira, C. Santos-Buelga, I.C.F.R. Ferreira. Chemical composition of wild and commercial Achillea millefolium L. and bioactivity of the methanolic extract, infusion and decoction. Food Chemistry, 141:4152-40 (2013).

[40] Raal, A. Orav, T. Pussa, C. Valner, B. Malmiste, E. Arak. Content of essential oil, terpenoids and polyphenols in commercial chamomile (Chamomilla recutita $\mathrm{L}$. Rauschert) teas from different countries. Food Chemistry, 131:632-638 (2012).

[41] S. Vitalini, G. Beretta, M. Iriti, S. Orsenigo, N. Basilico, S. Dall'Acqua, M. Iorizzi, G. Fico. Phenolic compounds from Achillea millefolium L. and their bioactivity. Acta Biochimica Polonica, 58:203-209 (2011).

[42] B. Benedek, N. Gjoncaj, J. Saukel, B. Kopp. Distribution of Phenolic Compounds in Middleeuropean Taxa of the Achillea millefolium L. Aggregate. Chemistry \& Biodiveristy, 4:849-856 (2007).

[43] R. Jaiswal, J. Kiprotich, N. Kuhnert. Determination of the hydroxycinnamate of 12 members of the Asteraceae family. Phytochemistry, 72:781-790 (2011).

[44] M. Lutz, C. Henriquez, M. Escobar. Chemical composition and antioxidant properties of mature and baby artichokes (Cynara scolymus L.), raw and cooked. Journal of Food Composition and Analysis, 24:4954 (2011).

[45] L. Panizzi, M. L. Scarpati. Constitution of cynarine, the active principle of the artichoke. Nature, 174:1062-1063 (1954).

[46] M.N. Clifford, S. Knight, N. Kuhnert. Discriminating between the Six Isomers of Dicaffeoylquinic Acid by LC-MS ${ }^{\mathrm{n}}$. Journal of Agricultural and Food Chemistry, 53:3821-3832 (2005).

[47] S. Deshpande, R. Jaiswal, M.F. Matei, N. Kuhnert. Investigation of Acyl Migration in Mono- and Dicaffeoylquinic Acids under Aqueous Basic, Aqueous Acidic, and Dry Roasting Conditions. Journal of Agricultural and Food Chemistry, 62:9160-9170 (2014).

[48] Y.J. Li, C.-F. Zhang, G. Ding, W.-Z. Huang, Z.-Z. Wang, Y.-A. Bi, W. Xiao. Investigating the thermal stability of six caffeoylquinic acids employing rapid-resolution liquid chromatography with quadrupole time-of-flight tandem mass spectrometry. European Food Research and Technology, 240:1225-1234 (2015).

[49] C. Xie, K. Yu, D. Zhong, T. Yuan, F. Ye, J.A. Jarrel, A. Millar, X. Chen. Investigation of isomeric transformations of chlorogenic acid in buffers and biological matrixes by ultraperformance liquid chromatography coupled with hybrid quadrupole/ion mobility/orthogonal acceleration time-of-flight mass spectrometry, Journal of Agriculture and Food Chemistry, 59:11078-11087 (2011). 
[50] M. Xue, H. Shi, J. Zhang, Q.-Q. Liu, J. Guan, J.-Y. Zhang, Q. Ma. Stability and Degradation of Caffeoylquinic Acids under Different Storage Conditions Studied by High-Performance Liquid Chromatography with Photo Diode Array Detection and HighPerformance Liquid Chromatography with Electrospray Ionization Collision-Induced Dissociation Tandem Mass Spectrometry. Molecules, 21:948-961 (2016).

[51] Farah, C.M. Donangelo. Phenolic compounds in coffee. Brazilian Journal of Plant Physiology, 18:23-36 (2006).

[52] Z. Hu, D. Chen, L. Dong, W.M. Southerland. Prediction of the interaction of HIV-1 integrase and its dicaffeoylquinic acid inhibitor through molecular modeling approach. Ethnicity \& Disease, 20:45-49 (2010).

[53] D. Srinath, U.K. Maheswari. Ultrasound Technology in Food Processing: A Review. International Journal of Current Advanced Research, 5:778-783 (2016).

[54] M. Dent, V. Dragovic-Uzelac, I. Elez Garofulic, T. Bosiljkov, D. Jezek, M. Brncic. Comparison of Conventional and Ultrasound-assisted Extraction Techniques on Mass Fraction of Phenolic Compounds from Sage (Salvia officinalis L.). Chemical and Biochemical Engineering Quarterly, 29:475-484 (2015).

[55] M.T. Tena, M.P. Martinez-Moral, P.W. Cardozo. Determination of caffeoylquinic acids in feed and related products by focused ultrasound solid-liquid extraction and ultra-high performance liquid chromatography-mass spectrometry. Journal of Chromatography A, 1400:1-9 (2015).

[56] M.P. Martinez-Moral, M.T. Tena. Focused ultrasound solid-liquid extraction and selective pressurized liquid extraction to determine bisphenol A and alylphenols in sewage sludge by gas chromatographymass spectrometry. Journal of Separation Science, 34:2513-2522 (2011).

[57] H. Li, B. Chen, S. Yao. Application of ultrasonic technique for extraction chlorogenic acid from Eucommia umodies Oliv. (E. ulmodies). Ultrasonics Sonochemistry, 12:295-300 (2005).

[58] C.S. Eskilsson, E. Bjorklund. Analytical-scale microwave-assisted extraction. Journal of Chromatography A, 902:227-250 (2000).

[59] B. Kaufmann, P. Christen. Recent extraction techniques for natural products: microwave-assisted extraction and pressurised solvent extraction. Phytochemical Analysis, 13:105-113 (2002).

[60] S. Hemwimon, P. Pavasant, A. Shotipruk. Microwave-assisted extraction of antioxidative anthraquinones from roots of Morinda citrifolia. Separation and Purification Technology, 54;44-50 (2007). 
[61] R. Upadhyay, K. Ramalakshmi, L.J.M. Rao. Microwave-assisted extraction of chlorogenic acids from green coffee beans. Food Chemistry, 130:184-188 (2012).

[62] H. Li, B. Chen, Z. Zhang, S. Yao. Focused microwave-assisted solvent extraction and HPLC determination of effective constituents in Eucommia ulmodies Oliv. (E. ulmodies). Talanta, 63:659-665 (2004).

[63] W. Routray, V. Orsat. Microwave-Assisted Extraction of Flavonoids: A Review. Food and Bioprocess Technology, 5:409-424 (2012).

[64] S. Masala, U. Rannug, R. Westerholm. Pressurized liquid extraction as an alternative to the Soxhlet extraction procedure stated in the US EPA method TO-13A for the recovery of polycyclic aromatic hydrocarbons adsorbed on polyurethane foam plugs. Analytical Methods, 6:8420-8425 (2014).

[65] Mustafa, C. Turner. Pressurized liquid extraction as a green approach in food and herbal plants extraction: A review. Analytica Chimica Acta, 703:8-18 (2011).

[66] R. Carabias-Martinez, E. Rodriguez-Gonzalo, P. Revilla-Ruiz, J. Hernandez-Mendez. Pressurized liquid extraction in the analysis of food and biological samples. Journal of Chromatography A, 1089:1-17 (2005).

[67] R. Ibanez,M. Herrero, J.A. Mendiola, M. Castro-Puyana. Extraction and Characterization of Bioactive Compounds with Health Benefits from Marine Resources: Macro and Micro Algae, Cyanobacteria, and Invertebrates. Marine Bioactive Compounds: Sources, Characterization and Applications, Chapter 2:55-98 (2012).

[68] R.M. Alonso-Salces, E. Korta, A. Barranco, L.A. Berrueta, B. Gallo. F. Vincente. Pressurized liquid extraction for the determination of polyphenols in apple. Journal of Chromatography A, 933:37-43 (2001).

[69] X. Lou, H.-G. Janssen, C.A. Crames. Parameters Affecting the Accelerated Solvent Extraction of Polymeric Samples. Analytical Chemistry, 69:1598-1603 (1997).

[70] . D.L. Luthria. Influence of experimental conditions on the extraction of phenolic compounds from parsley (Petroselinum crispum) flakes using a pressurized liquid extractor. Food Chemistry, 107:745-752 (2008).

[71] S. Erdogan, B. Ates, G. Durmaz, I. Yilmaz, T. Seckin. Pressurized liquid extraction of phenolic compounds from Anatolia propolis and their radical scavenging capacities. Food and Chemical Toxicology, 49:15921597 (2011).

[72] M. Jeszka-Skowron, A. Zgoła-Grześkowiak, T. Grześkowiak. Analytical method applied for the characterization and the determination of bioactive compounds in coffee. European Food Research and Technology, 240:19-31 (2015). 
[73] M. Antolovich, P. Prenzler, K. Robards, D. Ryan. Sample preparation in the determination of phenolic compounds in fruit. The Analyst, 125:9891009 (2000).

[74] C.D. Stalikas. Extraction, separation, and detection method for phenolic acids and flavonoids. Journal of Separation Science, 30:3268-3295 (2007).

[75] L. Gao, G. Mazza. Quantitation and Distribution of Simple and Acylated Anthocyanins and Other Phenolics in Blueberries. Journal of Food Science, 59:1057-1059 (1994).

[76] J.J. Mangas, R. Rodríguez, B. Suárez, A. Picinelli, E. Dapena. Study of the phenolic profile of cider apple cultivars at maturity by multivariate techniques. Journal of Agricultural and Food Chemistry, 47:4046-4052 (1999).

[77] Escarpa, M.C. Gonzalez. Fast separation of (poly)phenolic compounds from apples and pears by high-performance liquid chromatography with diode-array detection. Journal of Chromatography A, 830:301-309 (1999).

[78] M.J. Amiot, M. Tacchini, S. Aubert, J. Nicolas. Phenolic Composition and Browning Susceptibility of Various Apple Cultivars at Maturity. Journal of Food Science, 57: 958-962 (1992).

[79] B. Suárez, A. Picinelli, J.J. Mangas. Solid-phase extraction and highperformance liquid chromatographic determination of polyphenols in apple musts and cider. Journal of Chromatography A, 727:203-209 (1996).

[80] M.J. Amiot, M. Tacchini, S.Y. Aubert, W. Oleszek. Influence of Cultivar, Maturity Stage, and Storage Conditions on Phenolic Composition and Enzymic Browning of Pear Fruits. Journal of Agricultural and Food Chemistry, 43:1132-1137 (1995).

[81] L. Gao, G. Mazza. Characterization, Quantitation, and Distribution of Anthocyanins and Colorless Phenolics in Sweet Cherries. Journal of Agricultural and Food Chemistry, 43:343-346 (1995).

[82] H.M. Dawes, J.B. Keene. Phenolic composition of kiwifruit juice. Journal of Agricultural and Food Chemistry, 47:2398-2403(1999).

[83] Z. Fuzfai, I. Molnar-Perl. Gas chromatographic-mass spectrometric fragmentation study of flavonoids as their trimethylsilyl derivatives: analysis of flavonoids, sugars, carboxylic and amino acids in model systems and in citrus fruits. Journal of Chromatography A, 1149:88-101 (2007).

[84] H. Chen, Y. Zuo, Y. Deng. Separation and determination of flavonoids and other phenolic compounds in cranberry juice by high-performance liquid chromatography. Journal of Chromatography A, 913:387-395 (2001). 
[85] D. Jirovsky, D. Horakova, M. Kotoucek, K. Valentova, J. Ulrichova. Analysis of phenolic acids in plant materials using HPLC with amperometric detection at a platinum tubular electrode. Journal of Separation Science, 26:739-742 (2003).

[86] M. Brolis, B. Gabetta, N. Fuzzati, R. .Pace, F. Panzeri, F. Peterlongo. Identification by high-performance liquid chromatography-diode array detection-mass spectrometry and quantification by high-performance liquid chromatography-UV absorbance detection of active constituents of Hypericum perforatum. Journal of Chromatography A, 825:9-16 (1998).

[87] G. Zgorka, S. Dawka. Application of conventional UV, photo-diode array (PDA) and fluorescence (FL) detection to analysis of phenolic acid in plant material and pharmaceutical preparations. Journal of Pharmaceutical and Biomedical Analysis, 24:1065-1072 (2001).

[88] Y. Guan, T. Wu, M. Lin, J. Ye. Determination of Pharmacologically Active Ingredients in Sweet Potato (Ipomoea batatas L.) by Capillary Electrophoresis with Electrochemical Detection. Journal of Agricultural and Food Chemistry, 54:24-28 (2006).

[89] H.-L. Jiang, Y.-Z. He, H.-Z. Zhao, Y.-Y. Hu. Determination of chlorogenic acid and rutin in cigarettes by an improved capillary electrophoresis indirect chemiluminescence system. Analytica Chimica Acta, 512:111-119 (2004).

[90] B. Tang, D. Guo, Y. Li, H. Yang, Y. Huang, H. Li. Separation and quantitation of isomeric caffeoylquinic acids in honeysuckle products by low-pH microemulsion electrokinetic chromatography using tartrate as a chiral selector. Analytical Methods, 8:189-196 (2016).

[91] E. M. Risso, G. R. Peres, J. Amaya-Farfan. Determination of phenolic acids in coffee by micellar electrokinetic chromatography. Food Chemistry, 105:1578-1582 (2007).

[92] E.-H. Liu, L.-W. Qi, J. Cao, P. Li, C.-Y. Li, Y.-B. Peng. Advances of Modern Chromatographic and Electrophoretic Methods in Separation and Analysis of Flavonoids. Molecules, 13:2521-2544 (2008).

[93] E.C. Tatsis, S. Boeren, V. Exarchou. Identification of the major constituents of Hypericum perforatum by LC/SPE/NMR and/or LC/MS. Phytochemistry 68:383-393 (2007).

[94] G. Miliauskas, T.A. de W. van Beek, P.R.P. Venskutonis; E.J.R. Sudholter. Identification of radical scavenging compounds in Rhaponticum carthamoides by means of LC-DAD-SPE-NMR. Journal of Natural Products, 68:168-172 (2005).

[95] J.-P. Lai, Y.H. Lim, J.Su, H.-M. Shen, C.N. Ong. Identification and characterization of major flavonoids and caffeoylquinic acids in three Compositae plants by LC/DAD-APCI/MS. Journal of Chromatography $B, 848: 215-225$ (2007). 
[96] X. Xiao, J. Ma, F. Ge, X. Zhang, H. Yang, Q. Liang, Y. Wang, G. Luo. Application of near-infrared spectroscopy for the rapid analysis of Lonicerae Japonicae Flos solution extracted by water. Journal of Innovative Optical Health Science, 7:63-72 (2014).

[97] C.-L. Fan, Y.-M. Liu, Y.-Z. Cao, J.-J. Zhang, X.-M. Li, Z.-Y. Li, Y.-P. $\mathrm{Wu}$, T.-T. Guo. Determination of residues of 446 pesticides in fruits and vegetables by three-cartridge solid-phase extraction-gas chromategraphy-mass spectrometry and liquid chromatography-tandem mass spectrometry. Journal of AOAC International, 89:740-71 (2006).

[98] O. Kenny, J.T. Smyth, M.C. Hewage, P. N. Brunton. Quantitative UPLC-MS/MS analysis of chlorogenic acid derivatives in antioxidant fractionates from dandelion (Taraxacum officinale) root. International Journal of Food Science and Technology, 50:766-773 (2015).

[99] R. Gu, G. Dou, J. Wang, J. Dong, Z. Meng. Simultaneous determination of 1,5-dicaffeoylquinic acid and its active metabolites in human plasma by liquid chromatography-tandem mass spectrometry for pharmacokinetic studies. Journal of Chromatography B, 852:85-91 (2007).

[100] G. Dai, S. Ma, B. Sun, T. Gong, S. Liu, C. Li, W. Ju. Simultaneous determination of 1,3-dicaffeoylquinic acid and caffeic acid in rat plasma by liquid chromatography/tandem mass spectrometry and its application to a pharmacokinetic study. Analytical Methods, 7:3587-3592 (2015).

[101] E. Bajko, M. Kalinowska, P. Borowski, L. Siergiejczyk, W. Lewandowski. 5-O-Caffeoylquinic acid: A spectroscopic study and biological screening for antimicrobial activity. LWT - Food Science and Technology, 65:471-479 (2016).

[102] N.M. Clifford, W. Wu, J. Kirkpatrick, R. Jaiswal, N. Kuhnert. Profiling and characterization by liquid chromatography/multi-stage mass spectrometry of the chlorogenic acids in Gardeniae Fructus. Rapid Communications in Mass Spectrometry, 24:3109-3120 (2010).

[103] C.S. Gouveia, C.P. Castilho. Analysis of phenolic compounds from different morphological parts of Helichrysum devium by liquid chromatography with on-line UV and electrospray ionization mass spectrometric detection. Rapid Communications in Mass Spectrometry, 23:3939-3953 (2009).

[104] M.T. Tena, M.P. Martinez-Moral, P.W. Cardozo. Determination of caffeoylquinic acids in feed and related products by focused ultrasound solid-liquid extraction and ultra-high performance liquid chromatography-mass spectrometry. Journal of Chromatography A, 1400:1-9 (2015).

[105] Q. Shen, Z. Dai, Y. Lu. Rapid determination of caffeoylquinic acid derivatives in Cynara scolymus L. by ultra-fast liquid chromategraphy/tandem mass spectrometry based on a fused core C18 column. Journal of Separation Science, 33:3152-3158 (2010). 
[106] W.-B. Zhang, Z.-C. Wang, L.-Y. Zhang. Determination of 10 Caffeoylquinic Acids and 22 Flavonoids in Chrysanthemum Samples by Ultra-high Performance Liquid Chromatography-Diode Array DetectionTandem Mass Spectrometry. Chinese Journal of Analytical Chemistry, 41:1851-1861 (2013).

[107] P. Paya, M. Anastassiades, D. Mack, I. Sigalova, B. Tasdelen. J. Oliva, A. Barba. Analysis of pesticides residues using the quick easy cheap effective rugged and safe (QuEChERS) pesticide multiresidue method in combination with gas and liquid chromatography and tandem mass spectrometric detection. Analytical and Bioanalytical Chemistry, 389:1697-1714 (2007).

[108] N.I. Urakova, N.O. Pozharitskaya, N.A. Shikov, M.V. Kosman, G.V. Makarov. Comparison of high performance TLC and HPLC for separation and quantification of chlorogenic acid in green coffee bean extracts. Journal of Separation Science, 31:237-241 (2008).

[109] S.-M. Kim, Y.-F. Shang, B.-H. Um. Preparative Separation of Chlorogenic Acid by Centrifugal Partition Chromatography from Highbush Blueberry Leaves (Vaccinium corymbosum L.). Phytochemical Analysis, 21:457-462 (2010). 